Conceptualizing and operationalizing team task interdependences:

BIM implementation assessment using effort distribution analytics

\author{
Ajibade A. Aibinu (Corresponding author)
}

Melbourne School of Design, Faculty of Architecture, Building and Planning, The University of Melbourne, VIC 3010, Australia; aaibinu@unimelb.edu.au

and

Eleni Papadonikolaki

The Bartlett School of Construction \& Project Management, University College

London, UK; e.papadonikolaki@ucl.ac.uk 


\title{
Conceptualizing and operationalizing team task interdependences: BIM implementation assessment using effort distribution analytics
}

\begin{abstract}
Building Information Modeling (BIM) is a technological innovation currently at the forefront of digital transformation in the built environment. To achieve satisfactory outcomes with BIM, adopters need to find the most appropriate implementation strategy that is economically efficient. The research discussed here explores why and how distribution of effort spent on various tasks over project life cycle can be used as a metric for assessing and improving the performance of BIM implementation. Using quantitative data collected from a single in-depth case study of a BIM-enabled design and build project and subsequent interviews with three project actors and $11 \mathrm{BIM}$ experts, to validate and triangulate the findings, we explore the use of effort data to analyze and visualize effort distribution patterns. The visualizations revealed the dynamics of team collaboration and task interdependences in BIM-enabled work and their impact on effort distribution. Lack of timely input by the contractor, subcontractors and suppliers influenced unusual patterns in the distribution of efforts indicating potential sources of inefficiency and unnecessary costs in the BIM process; thereby revealing the pivotal role of procurement structure and suggesting the need for timely involvement of key project participants. The contribution of this work is twofold. Methodologically, effort distribution analytics can provide insights that managers can use to improve BIM implementation process. Theoretically, the findings can be used to support informed decision-making, control cost, optimize resources, manage cash flow and to structure fees.
\end{abstract}

Key words: building information modeling, construction, effort distribution, team collaboration, performance assessment 


\section{INTRODUCTION}

The famous 'MacLeamy curve', proposed by Patrick MacLeamy (2004), suggests that with BIM implementation task efforts will accrue in initial project stages and reduce the cost of changes later in the lifecycle. This curve was based on Paulson's (1976) curve that associated the influence of decision-making on construction project costs. According to MacLeamy (2004) BIM can facilitate coordination and collaboration by automating design and integrating people, product (the building) and the process for realizing it hence projects can be delivered faster (time), cheaper (cost) and better (quality).

Despite the widespread use of the MacLeamy time-effort distribution curve in industry and scholarly outlets to show BIM benefits, and the important role of BIM process performance assessment, there are only a few studies to date explaining time-effort distribution using systematic analysis of empirical time-effort data and what implications time-effort distribution carries for assessing implementation performance in BIM-based projects (except Lu et al., 2014; Lu et al., 2015; Manning and Messner, 2008; and Aibinu et al., 2014). Also, while the MacLeamy curve is useful for understanding the relation between projects organization and outcomes at the macro level, it provides limited information for individual disciplines or organizations to assess and monitor the distribution of effort for their tasks on the basis of which workflow improvement initiative can be implemented. The MacLeamy curve does not provide information on disciplinary and task differences. We also argue that there may never be one single effort distribution curve suitable for project and tasks (Aranda-Mena et al. 2009), effort distribution would be influenced by the context within which the project is embedded. In their work, Poirer et al. (2015) concluded that it is hard, if not impossible, to separate the impact of BIM use from the context thereby making comparisons among projects difficult and if not an impossible task. However, lessons learned from BIM implementation process on a project can inform other projects. 
Work effort is defined as the amount of attentional resources that a person expends towards tasks (Yeo and Neal 2004). Ergonomists and industrial engineers defined effort in terms of work output variables including motions used, time elapsed, fatigue factors, and weight, distances and amount of materials handled (Fleishman et al. 1984). Over many decades the Architecture, Engineering, Construction (AEC) sector and many researchers have examined project effort in terms of monetary value of work done and has led to the development and use of the famous S-curve (Skitmore 1988; Kaka 1999; Cheng et al. 2011). Regarding BIM implementation, we defined 'effort' as time elapsed. It is synonymous to person-hours expended on a task or activity, directly linked to labor budget. This study poses the question:

How can we conceptualize and analyze effort distribution in BIM implementation and how are tasks efforts interrelated during design in BIM workflow? What factor(s) influence the behavior of the effort distribution curve? and how can effort distribution analytics be used to assess the performance of BIM process?

This work is further divided into five main sections apart from the introduction and conclusion. The first section focusses on why organizations need to monitor the performance of the BIM implementation process. This is followed by the theoretical framework that presents relevant work and the points of departure, followed by the methodology and methods. The ensuing section presents the data from the case study and the findings and the subsequent section discusses this data by confronting them with the existing relevant literature. The theoretical contribution and the practical implications are presented before concluding the paper highlighting some limitations and future work. 


\section{THEORETICAL BACKGROUND}

\section{Importance of monitoring the performance of BIM process}

BIM process includes multiple human-computer interactions involving collaboration, communications, workflows, task interdependences and work processes which should be assessed towards greater efficiency (Eastman et al. 2011). In this regard, various organisations around the world have developed various metrics and benchmarking tools to assess and prequalify organisational and individual capabilities for BIM implementation (Kassem \& Succar, 2017). There are valid reasons for assessing performance of BIM implementation as described in the following paragraphs.

\section{BIM learning curve}

BIM adoption can be represented by a j-curve (Figure 1) whereby for organizations to reach a desired capability, there is a steep learning curve and loss of productivity below the current capability if adoption process is not planned for, assessed and monitored (adopted from Viney, 2005). Organizations need to find a smooth transitional strategy towards developing their BIM capability (Morgan, 2017). In that regards, the performance of BIM approach needs to be assessed and monitored in an ongoing manner to enable firms reach desired capability though learning. Even when a desired capability is reached, organization need to continue to engage in continue process improvement for further innovation in the BIM workflow to achieve greater efficiency because BIM adoption is more than just a transformation to a defined digital workflow, it is a continuous process (Milanovic Glavan, 2011).

\section{<Insert Figure 1 somewhere here>}

While BIM represents organization change and a learning curve for users both at organizational and project levels, there is not yet a single standard best practice BIM implementation process that put companies on the ideal path and there may never be one. Working with BIM is influenced by the context within which it is implemented 
(Kassem \& Succar, 2017). Although there are guidelines for implementing various aspects of BIM, e.g. BuildingSMART (2015), adopters of BIM need to find the most efficient implementation strategy and process that would maximize the benefit for their organization and for projects. Similar to any business process, the BIM process should have a strategic role in creating value for adopters. By consuming resources over a chain of activities and tasks intended to produce desired results, BIM should help organizations reach their business goals (Pourshahid, 2008). Thus, BIM process should be measured, monitored and analyzed for the purpose of learning, benchmarking and to inform improvement initiatives (Tagen, 2004, Milanovic Glavan, 2011). There is need for more research on Performance Measurement Systems (PMS) for BIM process. Kassem and Succar (2017) have highlighted the lack of benchmarking data on BIM implementation to compare markets and there exists a lot of ambiguity on how existing benchmarks are used for organisational development. PMS for BIM can help adopters compare BIM implementation across projects and can help them understand practices that differentiate successful from unsuccessful process. Productivity gains can be identified and used to continue to justify organizational change. BIM Process performance monitoring and assessment requires the development of appropriate statistics for monitoring performance and the development of methods for detecting the underlying issues and need for change (based on Harris et al.,1999). This study proposes effort distribution analytics as a method for post hoc and proactive analysis of the BIM process for greater efficiency.

\section{Ad-hoc BIM workflow is less efficient than traditional workflows}

In their search for a BIM workflow that brings the greatest efficiency, organizations involved in projects need to monitor their BIM process otherwise ad-hoc BIM process can lead to greater inefficiency for various reasons. While BIM workflow is being seen a method to eliminate this coordination problem in the AEC (Harrison 2010, p. 19), the BIM collaboration process is asynchronous under most circumstances (Cerovsek 2011) and typically involved fortnightly coordination sessions (Berlo, van \& Papadonikolaki, 2016). Whether disciplinary or collaborative 
BIM workflow, tasks in BIM workflow are highly interdependent (Jaradat et al. 2013, Papadonikolaki et al. 2017) and BIM success depends on coordination among the various tasks and disciplines. Figure 2 shows how an ad-hoc BIM workflow in design, documentation and design coordination can lead to inefficiency and according to Banks (2015) it can bankrupt a firm.

$<$ Insert Figure 2 somewhere here $>$

In relation to workflow in design, Figure 2 compares ideal BIM workflow, 2dimensional (2D) Computer-Aided Design (CAD) workflow, BIM combined with 2D CAD workflow and BIM without template workflow. BIM workflow combined with some 2D CAD work could be the most inefficient theoretically. In the ideal BIM workflow, designer spend more efforts on design and less in documentation and coordination when compared with non-BIM (2D CAD) workflow in which most efforts are spent on documentation (Banks, 2015). By investing in standardized templates BIM workflow can lead to much greater efficiencies than the idealized BIM workflow as numbers of BIM project using similar templates increases Banks argued (Banks, 2015). Going by Figure 2 analysis, identifying opportunities for standardization of repetitive, mundane and cumbersome tasks can bring greater efficiency in the BIM workflow.

While Banks' (2015) analysis refers to mono-discipline workflow for architectural discipline, the same principle can be used to analyze other tasks in BIM. Time-effort consumption can be observed and monitored under varying condition and scenarios. The famous McLeamy curve (Figure 3) proposed an idealized effort distribution in a collaborative BIM workflow which is built on the principles that early involvement of key project participants, early definition of project goals, intensified planning, open communication, use of appropriate technology to facilitate exchange of information seamlessly, and well-defined project organizational structure and leadership can lead to cheaper and better built assets constructed faster (AIA, 2007). While the McLeamy curve (2004) provides a good benchmark of effort consumption across project life 
cycle in BIM workflow, organizations involved on projects need to monitor their BIM process in search for a workflow that brings the greatest efficiency. Accordingly, this study will describe the use of effort distribution analytics as a method for assessing BIM process for greater efficiency.

$<$ Insert Figure 3 somewhere here>

\section{Team collaboration and tasks interdependencies can lead to waste in BIM implementation}

While BIM workflow promises greater efficiency, the way collaboration occurs among team members and the management of interdependences among BIM tasks can also lead to inefficiency if there are rework, idleness and waste of resources (Abdirad, 2017). For example, efficiency can be lost if Mechanical Engineering and Plumbing (MEP)-, structural-, and architectural- modeling start fully at the same time or if structural model and MEP models are developed based on an unconfirmed architectural model (Dossick \& Neff, 2010). Thus, the interfaces among structural, MEP and architectural models as well as interdependency among these tasks need to be managed to avoid inefficiency arising from fruitless use of time and effort (Dossick \& Neff, 2010). Similarly, late integration of structures and MEP requirements into architectural models can lead to wasted time later due to clashes between these models (Kokkonen \& Alin, 2016). Misalignment of BIM implementation and BIM management could prevent timely information exchanges at times when task interdependencies would benefit most (Dowsett \& Harty, 2018). Gade et al.(2018) presented many examples of poor coordination of interdependent tasks among design and construction specialists that resulted in delays in design or cost management solutions. For these reasons, understanding the complex nature of interdependencies among tasks can shed light into team collaboration dynamics and 
how they can be managed to increase efficiency in BIM workflow. Tasks interdependencies can be examined using effort distribution analysis of various tasks.

Malone and Crowston (1994) conceptualized some examples of interdependences among tasks, namely: (1) shared resources, (2) produced-consumer relationship, and (3) simultaneity constraints. Shared resources imply multiple tasks that share limited resources and thus, some form of resources allocation models is needed to manage them to reduce inefficiency. This form of dependency may also include task assignments, which requires allocation of scarce time to actors to perform their task (Malone \& Crowston, 1994). In a BIM-based process, modeling tasks, drawing activities and working drawings may share the same human resource since modelers may also be involved in drawing and working drawing activities (Papadonikolaki et al., 2015). Similarly, take-off activities and cost calculation may share resources consumption (Aibinu \& Venkatesh, 2014). Thus understanding how effort is distributed among the various tasks should give insight that organizations can use to optimize resources consumption (Aibinu et al., 2014). Inefficient resources allocation can lead to waste and delays.

Producer-consumer relationship dependency arises in situations where the output of one activity is needed for realizing another activity (Malone and Crowston, 1994). In the context of team collaboration, Thompson (2003) refers to this as 'reciprocal interdependence'. In construction projects, this can occur for example when information generated from one task is needed in order to start and or complete another task (Thompson, 2003). To avoid inefficiency, this requires proper work sequencing, tracking, information standardization and effective communication and protocols to ensure timely transfer of information (Archer, 2004). BIM process involves some level of producer-consumer relationship interdependence which is the most difficult to manage effectively, with the highest risks of inefficiency. It is also the most vulnerable to failure as failure of one task can have serious impact on another task (Kumar and vanDissel, 1996). In a BIM process, the modeling task forms the basis for drawings and working drawing while cost calculation would often 
rely on quantity take-off. An understanding of effort distribution among BIM tasks should facilitate the monitoring of producer-consumer relationship dependency across the BIM life cycle.

According to Malone and Crowston (1994) simultaneity constraints is a form of dependency where tasks need to occur at the same time or where they cannot occur at the same time. Thompson (2003) refers to this as 'sequential interdependence'. In BIM, some activities may occur concurrently while others cannot (Engwall 2012). 'Simultaneity constraint' is costly because of the need to plan and manage the sequential and concurrent nature of tasks (Kumar and vanDissel 1996). For example, early MEP and structural engineers' input is needed for architectural model and vice versa in each case thereby creating simultaneity constraint relationship (Papadonikolaki et al., 2017). Effort distribution analysis can promote greater understanding to support how these types of interdependencies can be proactively managed (Aibinu et al., 2014). Thus, there exists a close relationship between workflow efficiency, team collaboration, interdependences among tasks and effort distribution.

AIA (2007) provides the most comprehensive conceptualization of effort distribution over project life cycle for various disciplines in the context of Integrated Project Delivery (IPD). . The curves produced suggest that overall effort distribution in collaborative BIM depends on interdependences among effort curve for various disciplines and tasks. Currently, BIM process uses coordination matrix as part of BIM execution plan to manage interdependences among tasks, defining the priorities by discipline and or tasks, order for addressing issues and who is responsible. However, there is no standard coordination plan, organizations need to learn and discover how to manage tasks depending on project context (Giel \& Issa, 2013, Dossick \& Neff, 2010). We propose monitoring and assessing the performance of the BIM process using effort distribution to promote greater understanding of the dynamics of intradisciplinary and multi-disciplinary collaboration workflow. It can shed light into the 
complex nature of interdependencies among tasks and their impact and how they can be managed to achieve greater efficiency.

\section{RELATED WORK AND POINTS OF DEPARTURE}

\section{Trends in BIM implementation assessment}

This study proposed the use of effort distribution analysis to assess and monitor the performance of BIM implementation. Broadly speaking, there is a sheer volume of work on performance management framework for construction industry based on the concept of key performance indicators (KPI). Many KPIs have been identified which related to one or more of cost, time, quality, safety, scope, innovation, and sustainability (Kagioglou et al. 2001). To date, BIM implementation performance assessment has benefitted from this body of work (Poirier et al. 2015).

Besides the measurement of BIM impact on project indicators (Bryde et al. 2013), various frameworks for assessing BIM have also emerged including organizations self-assessments tools (Sebastian and Van Berlo 2010; Succar 2010; IU 2009), benchmarking (Sebastian and Van Berlo 2010), Owner Maturity Matrix (CIC Research Program 2012), organizational BIM capability (Succar 2013), BIM competency index for measuring employee's proficiency (Succar 2013), VDC score card (Kam et al. 2013), and Cost benefit analysis (Lu et al. 2014). In total, seventeen tools for assessing BIM organisational capability have been developed (Azzouz et al., 2018), focusing more on BIM adoption rather than BIM implementation. There have also been some attempts to measure BIM performance based on Return on Investment (ROI) using survey data (McGraw-Hill Construction, 2008). These frameworks are based on data provided by individuals in the form of questionnaires and surveys. Most of the BIM maturity models consist of general criteria with very limited practical measures for assessing BIM implementation (Abdirad, 2017). Few studies have used empirical data to determine returns on BIM investments by calculating the cost savings that BIM may result in or how those savings are being 
benchmarked (Giel and Issa, 2013). While some of these assessments are useful, they can yield skewed conclusions due to the subjective nature of the data input.

From a process perspective, BIM implementation effectiveness requires a broad spectrum of performance-relevant data including financial and nonfinancial as well as quantitative and qualitative data (based on Kueng and Krahn, 1999). Performance measurement in BIM implementation needs to be recurring (periodic) and continuous and the outcome must be targeted at providing feedback to process actors and middle management (based on Kueng and Krahn, 1999). To this end, there is need for evidence-based quantitative metrics and methodology for assessing BIM performance to facilitate monitoring and improving the process at organizational and project levels. Specific BIM assessment frameworks will be reviewed next.

Mom and Hsieh (2012) proposed a practical method for systematically assessing BIM technology implementation at a corporate level. Their method incorporates four main models: BIM perception, BIM adoption, BIM performance, and BIM capability maturity. These models were derived and consolidated from various existing BIM frameworks and approaches. Mom and Hsieh (2012) model can be used to evaluate and establish benchmarks for key BIM performance areas using key performance indicators (KPI).

Succar et al. $(2009,2013)$ developed a framework for understanding progression of BIM capability and maturity. The framework did not provide any insights into specific measures for assessing BIM performance. In developing the framework, three areas of BIM are identified namely BIM fields, BIM stages and BIM lenses. BIM fields include policy, technology (software implementation) and processes (workflow). BIM Stages are conceived as 'the major milestones to be achieved by teams and organizations as they adopt BIM technologies and concepts. Stages identified are, Pre-BIM stage, stage 1: Object-based modeling, stage 2: model-based collaboration, stage 3: network-based integration. In another study, Succar et al (2012) proposed metrics and benchmarks to assess the overall performance and 
benefits derived from BIM. Their work identified five BIM framework components namely: BIM capability stages, BIM maturity levels, BIM competencies, organizational scales, and granularity levels. The five BIM framework components can enable various forms of assessments for stakeholders to measure and improve their BIM performance. This work was broad and insightful but theoretical and did not operationalize BIM performance. A few other maturity models contributing to the assessment of BIM process maturity are discussed next.

First, the BIM proficiency model developed by the Indiana University Architect's office (IU, 2009) can be used to assess the proficiency of a respondent's skill at working in a BIM environment. Second, the BIM QuickScan, developed by TNO Built Environment and Geosciences in the Netherlands (Sebastian and Van Berlo, 2010) can be used for benchmarking organizational BIM performance to provide insight into the current BIM performance of a company. The tool consists an evaluation of four areas within an organization namely mentality and culture, organization and management, information structure and information flow, tools and applications and the data are collected through online data collection instrument. Third, the COBIT Maturity Model (Control objects for information and related technology) was developed by the Information Systems Audit and Control Association (ISACA) and the IT Governance Institute (ITGI) to measure how well developed the management processes are with respect to internal controls. It aimed at enabling the development of clear policy and good practice for IT control throughout organizations (Lainhart, 2000). Fourth, the National Building Information Model Standard (NBIMS) proposed a BIM Capability Maturity Model to be used internally by organizations to map their current BIM implementation and establish targets for further developing internal capabilities. It comprised of 10 levels or increasing maturity across 11 aspects namely, data richness, life-cycle views, roles or discipline, change management, business process, timeliness/response, delivery methods, graphical information, spatial capability, information accuracy, and interoperability IFC support. Fifth, the 'Capability maturity model integration' (CMMI) developed by 
Software Engineering Institute (SEI, 2006) of the Carnegie Melon University is a process improvement approach that helps integrate traditionally separate organizational functions, set process improvement goals and priorities, provide guidance for quality processes, and provide a point of reference for appraising current processes. Quantitative and process-related data analyzed with statistics might be used in the appraisal (Poirier et al, 2015).

In relation to BIM implementation, organizations would benefit from process-based performance assessments which provides insight for improving and optimizing the BIM workflow both at organizational level and project level. However, all frameworks reviewed above utilise data provided by individuals in the form of questionnaires and surveys and fail to consistently operationalize how criteria are measured and performance is assessed. At the same time, most of these assessment tools focus on the adoption of BIM and not on the implementation which is about how it is used. There is relatively little research exploring the use of empirical and quantitative data from real-life projects as a means for assessing the performance of BIM process to facilitate monitoring and initiate improvement initiatives. Such data should be meaningful in practice, process-based and should potentially correlate project and organizational outcomes such as workflow efficiency, and productivity.

This study proposes the use time-effort distribution analysis, a quantitative and visual method, to analyze BIM process for greater insight into the performance of BIM workflow in relation to how time is expended on tasks, task interdependences and efficiency.

\section{Time-effort distribution research in construction}

There are only five studies on time-effort distribution in relation to BIM, to the best of the authors' knowledge. Other BIM case studies are based on descriptive assessment of time-effort based on the researcher's observations about effort put into different activities in the BIM process and not actual effort data (e.g. Wakefield et al., 2007). In a study, Manning and Messner (2008) present evidence of early intensified 
project planning with BIM using two healthcare project case studies. In one of the case studies, a large proportion (29 months) of the 36 months project development period was expended on programming, conceptualization, approval, and contracting highlighting the benefits and challenges of this early effort and level of detailed achieved at conceptual design. No data on actual time expended over the project development process was analyzed to understand interdependences among various tasks. The second case study explored by Manning and Messner (2008) used personhours to measure effort expended but only showed how BIM helped save time when compare to the existing practices before BIM was implemented. The distribution of time-efforts expended is not systematically analyzed to explore interrelationships between tasks and lessons learned.

Aranda-Mena et al. (2009) explored the differences in effort distribution curves between traditional and BIM-enabled projects using qualitative analysis of respondents' perceptions instead of a quantitative measure of actual effort. A visual representation of respondents' views showed inconsistencies in the respondents' perception of effort distribution in traditional project delivery method (Aranda-Mena et al., 2009). Respondents believed that effort distribution curve for traditional method is evenly distributed between schematic design phase and detailed design phase rather than at the later stage of the project (Aranda-Mena et al., 2009). The study did not identify any consensus concluding that a single model of effort distribution was not plausible which agrees with AIA (2007). Despite the potential benefits of effort distribution analysis, the use of real-life time-effort data is hard to come by in the literature and in practice (Aibinu et al., 2014). Aibinu et al (2014) measured actual time-effort curve using quantitative approach but their work is based on design stage effort curve in relation to only 'project management effort' and 'working drawings' effort in design stage of BIM workflow. The study is not based on any conceptualization of effort distribution in relation to workflow and task interdependences. 
Lu et al. (2014) used time-effort distribution curves to evaluate the costs and benefits of BIM implementation in construction projects concluding that a slight increase in effort at the design stage through BIM implementation will significantly improve the execution of a construction project overall. In a related study, Lu et al. (2015) analyzed and compared actual time-effort distribution curve for a BIM and a nonBIM project procured with design-bid-build (DBB) method. Effort was depicted as priced efforts $(\mathrm{PE})$ which was measured as interim payments made by the client to different participants for services rendered. The total monthly PE for all consultants is aggregated to determine the total project effort for that month. The PE for 57 months and 76 months was graphed for BIM and non-BIM projects respectively after normalizing the data so that the two projects are comparable in terms of the gross floor area and after the effect of inflation was accounted for. Based on the graphical representation of the effort data over the design and building construction stages, the study concluded that 'BIM implementation does incur extra expenses at the design stage but the expenses will be offset at the building stage' (Lu et al., 2015). According to anecdotal data, the time-effort curve by MacLeamy is empirically substantiated.

\section{Points of departure}

This study will differentiate from the work by Aranda-Mena et al. (2009) by using quantitative effort data from real-life project instead of perception data. It will extend Aibinu et al (2014) by examining effort curves for seven tasks at the design stage as well as conceptualize interdependences among the tasks and the impact. Whereas the analysis by Lu et al. $(2014,2015)$ was the first attempt to compare the actual timeeffort curves for BIM and non-BIM projects, their work should be interpreted with caution because of the metric used to measure effort and the use of Design-Bid-Build (DBB) procurement case study. Although the current study is not intended to confirm the MacLeamy curve nor seeks to compare a BIM project with a non-BIM project, it will depart from the Lu et al. (2015) work by proposing and using actual time (in person-hours) spent on tasks at every point in time as a metric for analyzing effort distribution instead of priced efforts based on interim payments to participants (PE). 
Also, this study used a BIM-enabled Design and Build (DB) project case study instead of DBB.

In relation to the work by Lu et al. $(2014,2015)$, first, the use of interim payments as a proxy for priced effort may not represent the actual effort because the priced and paid effort is often based on fees agreement reached through market competition and negotiation at the onset of project. The total fee may have been exaggerated or underestimated owing to premium for perceived risks associated with the BIM process and the lack of experience. Also, Lu et al.'s (2015) work assumed that interim payments for professional services are based on agreed and assumed payment structure, either monthly or milestone, with each participant. However, interim payments pattern may by no means reflect the actual effort spent at various stages. It cannot not reveal actual efficiency or inefficiency. Second, the time-effort curves developed by Lu et al. $(2014,2015)$ is based total combined effort of all the participants whereas a single effort distribution curve is not sufficient for understanding the BIM workflow to facilitate monitoring and improvement initiative for enabling greater efficiency. In the current study, the relationship between effort distribution curves for different tasks should provide greater insight into team collaboration, the impact of task interdependences, efficiency gains and loss and areas where improvement initiatives can be implemented for better outcomes.

The outcome of the approach proposed in this study, if used at the organizational level for assessing internal BIM workflow, will enable managers to understand the efforts and the timing of various teams in relation to one another. The same is true of project level effort analysis (collaborative BIM). In practice, too early effort input to some tasks may be counterproductive and may lead to rework. Also, in relation to the case study used by Lu et al (2015), DBB is not an arena for understanding the full benefit or performance of BIM approach in that it adds to the fragmentation of information between design disciplines and between design and construction (Holzer, 2015). Also, the theoretical time-effort curve for BIM by MacLeamy (2004) (Figure 2 ) is in relation to IPD procurement. For these reasons, whether or not Lu et al's 
(2015) work substantiated MacLeamy time-effort curves, as claimed by the authors, should be interpreted with caution. A BIM-enabled DB project is more integrated and in the absence of IPD project case study, DB procurement approach could support BIM coordination, by creating an environment that fosters concurrent interactions among team members and tasks. Using a single in-depth DB case study, this study examines effort distribution among seven tasks during design, and by that means conceptualizes the interdependences among them, as well as investigate the potential practical uses of effort distribution analytics, the challenges and future directions.

\section{RESEARCH METHODOLOGY AND METHODS}

\section{Research rationale}

The study follows an empirical epistemology, attempting to acquire and assess knowledge derived from practical and observable first-hand experience in the field rather than theoretical explanation. The research philosophy is realism as the study is based on observable phenomena that have provided credible data and facts. Critical realism paradigm is useful for facilitating a dialogue and compatibility assessment between quantitative and qualitative approaches (Maxwell and Mittapalli, 2010). However, the issue of BIM implementation in construction generates multiple interpretations from actors, social phenomena are involved, e.g. collaboration, management, tasks and actions and these are pertinent to subjective meanings. Therefore, the study allows interpretivism and could be best described as critical realism philosophy, observed through a realism ontology, as the "study of being" (Blaikie, 2010) from the researchers' perspective is objective and independent of their beliefs.

The research approach followed in this study is abductive, as the multiple sources of data allowed us to visit the fieldwork and discuss it. The research strategy was a single-case study and the data were collected with mixed methods involving quantitative methods, interviews and focus groups. The data collected were of varying types and in principle mixed methods were used to strengthen the validity 
and credibility of the study (Miles and Huberman, 1994).The quantitative data were collected through surveys of person-hours information and analysed statistically in an analytical manner. The qualitative data were collected through interviews and were analysed with content analysis and presented through quotations and discourse.

\section{Research setting}

This study presents an approach for evaluating the performance of BIM process using the concept of effort distribution and task interdependences. The study is a single case study research. It uses mixed methodology comprising both quantitative and qualitative data collection and analysis through effort distribution analysis and interviews for research validation respectively. Creswell (1994) put forward the idea of combining and triangulating among different sources of data to enhance research accuracy. No comparison is made with a non-BIM project, instead the concept of timing of efforts as put forward by McLeamy (2004) curve has been used to analyze the data. Apart from the combined total effort curves for individual tasks, the interrelationships among tasks across design phases are examined to explore the course the project had taken and on that basis issues are identified which can form the basis for improving BIM workflow in the future. Departing from McLeamy (2004) curve, we argued that in any attempt to leverage effort curve to improve the performance of BIM implementation from process management perspective, differences in projects tasks effort need to be accounted for. The McLeamy curve assumes the use of integrated project delivery procurement which is not possible on all projects (Holzer, 2015). In this study, a BIM-enabled DB project has been selected as a case study because it is more integrated than DBB and a better arena for exploring the BIM workflow effort curves. 


\section{Data collection}

\section{Mixed methods}

Overall, a mixed methods approach was deployed. Quantitative effort data was collected from a real-life BIM-based DB project case and was used to produce effort curves of seven BIM process related tasks and charts showing how total effort was expended. The quantitative effort was the first part of the research and it was then followed by a qualitative phase. After the quantitative data presentation and analysis, the curves and charts were then presented to 3 project participants. Thereafter, they were presented to the 11 practitioners who are external to the project without disclosing the details and identity of the project. The qualitative interviews explore the usefulness of the charts in practice and lessons that can be learned in relation to the behavior of the curves as well as opportunities for achieving greater efficiency and improvements in BIM workflow in future projects. This was done for research communicative validation (Sarantakos, 2005, p. 86) and data credibility by involving the participants to check data accuracy and add depth and richness to the data. The project website and project work plan were also used as secondary data for triangulation.

\section{Effort distribution analysis process}

The data collection and analysis were conducted in the following steps:

- Step 1 - Collection of effort data and time of effort at task level.

- Step 2 - Data processing by normalizing each effort data points.

- Step 3 - Visualization of data using effort distribution curves.

- Step 4 - Presentation of the curves to project actors and experts and data interpretation to learn and improve BIM process for greater efficiency. 


\section{Step 1 - Collection of effort data and time of effort at task level}

We first define 'time' and 'effort'. Time is the 'period during a project process' (Lu et al., 2015). It can refer to intervals of days, weeks, or months, depending on the level of details at which the project process is studied (Lu et al., 2015). Work effort can be broadly defined as the amount of attentional resources that a person expends towards job tasks (Yeo and Neal 2004). It can be described in terms of consistency, persistence, and intensity of individuals to completing some tasks (Campbell 1990). Ergonomists and industrial engineers defined effort in terms of work output variables such as motions used, time elapsed, fatigue factors, weight, distances and amount of materials handled (Fleishman et al. 1984). In the field of software engineering, 'effort' data has been identified as the most useful data for assessing the validity of schedules, costs, quality, etc. of new projects by which new projects can be compared against similar projects (Jones 2004).

In this study, we conceive 'effort' as time elapsed i.e. person-hours expended on a task. The benefit of 'person-hours' is that it can be linked to budget and fee structure which is critical to organizations bottom line. We argue that person-hours expended is a better representation of actual effort expended on tasks when compared with 'interim payments' made by the client as proposed by Lu et al $(2014,2015)$. During project process, participants such as the client, designers, consultants, contractors, etc. will contribute their effort (disciplinary effort) at different stages of the project lifecycle. At the same time, the efforts expended by each participant are directed towards various tasks in their individual work (mono-disciplinary workflow). Tasks are interdependent within and across disciplinary work because no participant possess all the information needed to complete their work on design and construction. Our study is not intended to measure or compare productivity of individual staff but to assess how time was spent across task involving teams which is not new in the broader organizational literature. Because of the complexity and interdependencies among task in construction projects, time expended on tasks is not necessarily a result 
of poor productivity of teams but efficiencies of work processes and the management of task interdependences.

For greater insight into BIM workflow and efficiency of BIM process, this study proposes effort distribution analysis at task level. Data can be recorded for each task separately against the date. On a day where there was no effort expended, an effort of zero man-hour can be recorded so that days with no active effort can be reflected on the effort distribution curve and queried. It could indicate period of delay as result of a prior inefficiency etc. Also, the combined total person-hours expended on all the tasks for each day can also be recorded against the date to enable analysis of combined effort curve. The project milestones in relation to design stages can be noted.

In this case study, the concept of Level of Development (LoD) was adopted by parties. LoD describes the dimensional, spatial, quantitative, qualitative, and other data included in a design model (AIA G202-2013). It indicates the level of information embedded in the model. While there is no universally agreed upon definition of what content constitutes each LoD, the parties involved in a project can specify in their BIM execution plan. The concept of LoD is vague and problematic in practice because LoD plans are seldom followed in the design process and as a result several models may be delivered with a higher or lower LoD-level than necessary leading to many changes (Grytting et al., 2017). For the analysis and for greater clarity, we translated the LoDs into the design stages adopted by the MacLeamy curve (Figure 3) after discussion with two practitioners. Effort data were collected for the seven tasks of: project management, quantity extraction, cost calculation, modeling, drawing activities (including working drawings). Effort expended on 'other calculations' and 'general activities' were also collected. These tasks were selected for convenience because a single BIM management firm was responsible for these tasks. 
Step 2 - Data processing by normalizing each effort data points

The data obtained from the project administration record were absolute person-hours. To anonymize the raw data (person-hours) as well as make the effort distribution curves comparable across the eight activities we normalize each effort data point as follows:

Effort $($ normalized $)=\frac{\text { person-hours expended }}{\text { total hours expended on all the } 8 \text { activities during BIM process }}$.

Step 3 - Visualization of data using effort distribution curves

The normalized effort data and the time along project life cycle can be used to show the time-effort curve on a two-dimensional coordinate system. The resulting graph can be represented in the form of column, area, or line and can be fitted with be linear or non-linear (Kshirsagar and Smith, 1995) trendline such as linear, exponential, polynomial, logarithmic, and power or other suitable distribution. The effort pattern can be queried. Through the visualization stage, critical interfaces among tasks, effort peaks and off-peaks can be identified and noted to be then discussed with project actors and experts. Where the project context is similar the insights can also be compared across projects. The implications of curves can also be explored, in terms of how they can inform process improvement in BIM implementation across tasks and projects.

Step 4 - Presentation of data to project participants and independent experts external to the project and data interpretation

The afore-described visualization outcome in curves can then be presented to experts and those involved on the project and can be analyzed and queried and lessons learned can be explored. The goal is to use this exploration for data validation and for project post-completion evaluation process, an elusive practice in project management. Based on the insights, the effort curves lessons learned can be used to proactively plan and improve future BIM process. After being visualized, the data 
were presented to 14 practitioners to interpret them by asking them to identify the striking features of the curve and factors that may have influenced the curve as well as how the curve can be improved to achieve greater efficiency in the BIM process. Of the 14, three are participants of the project case study (i.e. BIM consultant, Cost Manager and Project Leader) and 11 are practitioners external to the project and are not familiar with the identity of the project. Factors that may have influenced the behavior of the curves were explored through this discussion. The interviewees were also asked to discuss the implications of using the curves for organizational learning. Table 1 shows the profile of the interviewees and their expertise.

$<$ Insert Table 1 somewhere here $>$

\section{THE CASE STUDY AND FINDINGS}

A real-life BIM-enabled design and build project, hereafter referred to as Project A for anonymity, was studied to explore how effort expended on BIM was distributed over time. The analysis covered two aspects: (1) total effort distribution combining all tasks (2) effort distributions for each task namely quantity extraction, cost calculation, modeling, drawing activities (including working drawings), project management, general activities and other calculations. The effort curve revealed the evolution of effort over time i.e. the rate of effort over the project lifecycle.

\section{Case study context - project organization, BIM use, software and outcomes}

The project is a housing project of 40 rental apartments using industrialized building systems and was procured through a DB approach. Architects were engaged by the client to develop the design up to schematic design which formed the basis for tender and contractor selection. BIM was not a requirement in the contract, the use of BIM was the contractor's choice and proposal to the client during tender with the goal to achieve the client's requirements, the most important being to achieve the lowest 
'economic cost' and save implementation time. BIM use was implemented to challenge the existing project coordination structure. The BIM managers were responsible for the modeling, drawings, quantity extraction, cost calculation as well as overall BIM management and coordination from 'design development' (DD) to 'construction documentation' (CD). Various suppliers and subcontractors were also selected by the BIM managers, after consulting with the contractor, based on their experience with BIM. The BIM managers were responsible for not only the overall management of the project, as project managers, but also for the generation of the BIM models based on models produced by the designers and several subcontractors, as coordinators.

Therefore, the BIM coordination structure is highly centralized with the BIM managers responsible for driving the entire process. A project website hosted on the servers of the BIM managers was used as a Common Data Environment (CDE) to share project information using the BIM collaboration format (BCF) for model coordination and management of issues. The BIM process was supported by BIM Management plan agreed upon by parties at the BIM kick-off meeting in the project early stage. The BIM management plan contains agreement regarding technology (software), process and responsibilities as well as deliverables and timelines etc. Open BIM was adopted and so several software was used by the various disciplines/parties as agreed via BIM management plan. Some challenges included time pressure because of the contractual obligations and late completion of tasks by some parties. There were many changes in the design phase. The contractor's expectations were too high because it was their first BIM project, which also put work and time pressure on the other parties. The BIM managers had to work overtime to meet the requirements their BIM management function and central coordination role. BIM was used clash detection, working drawings, design visualization, quantities-take off and cost calculation, and exchange of information.

The outcome of the BIM process was that design errors and clashes between architectural, structural and services models were identified and resolved prior to 
construction; the project time was shortened by $40 \%$. The project was scheduled for completion within 191 working days, but practical completion was achieved within 115 working days (40\% shorter). All involved parties, especially the client was satisfied because of the quality of the building delivered. Up to 591 clashes were resolved during design thereby minimizing issues resolution during construction and promoting better quality building. The project experience provided all participants

opportunity increase their knowledge about BIM process. One interviewee stated it is a successful project. There is $40 \%$ shorter construction and preparation time, and we achieve a quality final product and all parties have better understanding of the process. Our clients are satisfied'(Interviewee C). While the BIM process was beneficial for the project, it was revealed that it did not generated returns on effort expended by the BIM managers. 'Although the process was a successful BIM project, unfortunately we have largely exceeded the estimated hours.... and so in terms of return it's not good for us 'interviewee $\mathrm{C}$ added referring to the gap between budgeted/claimed effort and actual effort expended. Effort distribution analysis should provide insight into how effort was expended and how it can be improved in the future for greater efficiency not only for the benefit of the project but for the participants' internal workflow. The lessons learned can help put BIM adoption path of organizations on the ideal path (Figure 1) instead of steep learning path, thereby smoothing digital transition and promoting learning.

\section{Visualizing Effort Distribution}

The aggregated effort for the seven tasks was graphed. The proportion of total effort expended and the proportion of total stage effort for each task across the project phases was also estimated. This was followed by graphing the individual tasks effort against time. About 300 effort data points were used for the analysis. 


\section{Effort expended on tasks}

Figure 4 shows the relative effort spent on each task as a percentage of total effort spent on the seven tasks while Figure 5 shows the distribution of total effort expended across the phases and phase length as a $\%$ of total length of design phase. Overall, drawing activities (41\%), project management (19\%), modeling (11\%) are the top four tasks consuming the most effort in the BIM process (Figure 4). This was followed by quantity take-off (8\%), other calculations (8\%) and cost calculations (7\%). Although according to Figure 5, Pre-DD period took longer on the project timeline (34\%) when compared with DD (25\%) and CD (40\%) the least effort was expended at this stage (pre-DD) (7\%). Evidently, most of the design effort was expended at DD (50\%) followed by CD stage (43\%) and pre-DD stage (7\%) - Figure 5.

$<$ Insert Figure 4 somewhere here $>$

$<$ Insert Figure 5 somewhere here $>$

When Figure 4 was presented to experts, during the qualitative phase of the study (Step 4), there was consensus that the dominance of drawing task efforts was not unexpected because BIM process currently involves a lot of 2D drawings activities for construction implementation (i.e. shop drawing for site works) and for building approvals by local authority at DD and CD stages. According to the experts interviewed, checking and approval of drawings is still based on 2D drawings in most cases. One of the experts (Interviewee J) stated 'clients still want good drawings and you have to do a lot of $2 D$ work to make drawings look nice'. The eleven interviewees agreed that in the future the effort expended on drawing activities might bring greater efficiency as BIM matures and approvals by clients and local authority are done based on models. One expert (Interviewee F) said some large clients are starting to receive only 3D BIM with no 2D drawings. Another expert believed that only about $2 \%$ of Drawing effort is typically expended towards building approval, the majority are a result of implementation drawings as well as late changes at CD stage. 
Interviewee $\mathrm{L}$ stated that until workers on site can use models with tablets during execution of work, 2D drawing production will continue to consume a lot of efforts in BIM. Interviewee $\mathrm{N}$ added 'if you look at this again in 5 years, the curve would have changed because in my opinion we don't need drawings anymore; if you have the BIM model and you give everyone iPad or laptop and you have your google glass and you have like manual on your augmented reality (AR) or virtual reality (VR) glass, then workers don't need drawings'. Experts also agreed that in the current BIM process, not all details are included in the model for efficiency reasons often necessitating more work on 2D drawing annotation and checking and consuming a lot of effort which can vary from project to project. Interviewee F stated, 'If there are no many details and elements in $3 D$ then you have to do lot of work in $2 D$ work to show features that are not in $3 D$ and it may be more efficient to put some details on $2 D$ sometimes'. This underscores the argument that there may never be a single standard effort curve.

Thus, a project-based post completion analysis of effort distribution would provide greater insight for understanding and for improving BIM process when compared to a standard and generalized effort curve proposed by MacLeamy (2004). However, generalized effort might provide additional information about all projects on the average.

\section{Total effort distribution}

Figure 6 presents the total effort distribution. Figure 7 presents the cumulative $\%$ total effort versus the \% time elapsed into the project. Although a comparison of phase efforts (Figure 5) is consistent with the MacLeamy curve (Figure 3) because the highest effort occurs at DD stage and decline towards CD stage but overall effort distribution from DD to CD stages is unusual. Two humps can be observed (Figures 5 and 6) instead of one, the first at DD stage followed by a decline (at early CD coordination of design models with subcontractors' models) and then the second 
hump (at end of CD - working drawings production). At the CD phase with working drawings production, a higher than expected effort level for a BIM projects can be observed, and it is unusual. 2D drawing activities was responsible for this second hump (Interviewees $\mathrm{A} / \mathrm{B} / \mathrm{C} / \mathrm{J} / \mathrm{N}$ ) and it is very common in the current BIM practice and it is an area needing greater efficiency in practice (Interviewee $\mathrm{G} / \mathrm{J} / \mathrm{N}$ ).

$<$ Insert Figure 6 somewhere here $>$

$<$ Insert Figure 7 somewhere here $>$

According to Figure 7, the overall total effort distribution started from zero and grew up to $6 \%$ at $8 \%$ time elapsed after which it remained unchanged for a period up to $32 \%$ elapsed time and then it rapidly grew and peaked to $46 \%$ in the early stage of DD at $44 \%$ elapsed time. During DD around 50\% effort had been consumed at $52 \%$ elapsed time. When the chart was presented to three experts who were involved on the project (Interviewees $\mathrm{A} / \mathrm{B} / \mathrm{C}$ ) the behaviour of the curve was easily recognizable. 'Project A' was awarded to the contractor at the end of schematic design (SD). The contractor proposed to use BIM as a process and platform for design development (DD) and for coordinating several subcontractors' models to achieve construction documentation (CD) of working drawings and shop drawings prior to construction.

From the interviews, it was revealed that the little early effort at pre-DD phase were expended on kickoff meeting and agreement on execution phase and transfer of document to different parties as well as preparation of common data environment for managing the project. The inactivity between $8 \%$ and $32 \%$ time elapsed was a result of contractual agreement to start DD as shown on the curve. This was triangulated by looking at the project work plan. When experts were asked for the possible reasons, it was suggested that it could be as result of client's workload and other ongoing projects (the contractor in this case). They did not believe the long inactivity had any impact on the efficiency of the BIM process because the start of DD in Figures 6 and 7 was based on contract agreement. However, it may have contributed to the rapid growth in effort at DD hence work pressure in the early stages of DD. According to 
the experts (Interviewees $\mathrm{A} / \mathrm{B} / \mathrm{C}$ ), the rapid growth in effort and the peak was directed towards preparation of model (federated architectural, structural and MEP) and output drawings needed for local authority building approvals. Thus, the rapid growth and peaked effort at DD stage was not unexpected.

During DD, although effort peaked early in the phase it was followed by another short period of inactivity between $44 \%$ and $50 \%$ time elapsed. It was found that the short period of inactivity during DD is the period when the parties were awaiting approval before the design models can be developed further, ready for construction documentation (CD) phase including integrated with subcontractors models. At DD, the gradual rise in effort during the period from $52 \%$ to $60 \%$ time elapsed were concentrated on finalizing DD models based on the local authority building approvals (Figure 7). The efforts from the end of DD stage continued to grow into the early CD phase $-60 \%-68 \%$ time elapsed (the shortest phase) and peaked very quickly towards the end. Early CD effort involves coordination of subcontractors and suppliers' models, further clash detection and adjustment of approved DD model. Thereafter, there was a short period of inactivity into CD stage (68\% - 71\% time elapsed), and which also involved application for final approvals. From this point effort grew again till it peaked at $87 \%$ time elapsed which is shortly after the commencement of site works.

When the total effort distribution was fitted with a polynomial trendline (Figure 5), the curve suggests that the initial stage the BIM process absorbed a lower level of effort which is equivalent to the initial project management activities, and as DD commenced more effort was absorbed to reach the first peak and thereafter a second peak was reached at $\mathrm{CD}$ coinciding with final drawing and working drawing efforts.

\section{Tasks efforts distribution}

Figure 8 shows tasks efforts as $\%$ of total stage effort while Figure 9 shows the area graph of effort distribution for individual tasks overlaid on each other depicting interdependencies among tasks. They give insights into the impact of tasks efforts and 
task interdependencies on the behavior of total effort distribution curve (Figure 6). The efforts at the early stage (Pre-DD) were directed at project management activities (54\%), quantity extraction (34\%) and some early cost calculation (9\%) (Figure 8). Project management activities included exchange of documents among the various parties, preparation and agreement on BIM execution plan and other project commencement activities. The rapid built-up of effort at DD phase involved all the 7 tasks. Drawing activities (27\%), modeling (18\%) and project management (14\%) are the top three areas of effort consumption followed by other calculations (13\%), cost calculation (12\%), general activities (11\%), and quantity extraction (6\%). Tasks interdependencies are most critical at this stage (Figure 9) suggesting critical interface among the tasks. Application for building permit requires preparation of 2D drawings from DD model which includes annotation and checking of drawings. It also involves project management activities. Model preparation included federated architectural, structural and MEP models while project management at this stage transferring models to different parties, model review and confirmation. Preparation of working budget using model-based approach was also a major activity at this stage $(12 \%)$. Because of the high level of task interdependences work pressure at DD stage can impact a project and influence efficiency if not well planned and managed.

$<$ Insert Figure 8 somewhere here $>$

$<$ Insert Figure 9 somewhere here $>$

The second rapid growth in effort towards the end of DD and throughout CD architectural, MEP and structural, comprised of intense project management (33\%), modeling (18\%) and some drawing activities (16\%) (Figure 8). Project management at this stage were directed coordination of 3D models of several subcontractors to realize $\mathrm{CD}$, while modeling activities include incorporation sub-contractor and suppliers' models with CD information embedded to enable fabrication, clash detection of all design models, and model adjustments. Project management at this stage also involved the final application for building approvals. The continuing 
growth of efforts into $\mathrm{CD}$ working drawings to the start of site works and thereafter was directed at preparation of drawings (83\%) and project management (14\%). This involves processing changes, control of working drawings, annotations and revisions in preparation for the works.

\section{Impact task interdependences and task efforts on total effort curve}

During the interviews, one expert (Interviewee J) queried why drawing activities started before modeling as shown in Figure 10(a) and 10(b) describing this as anomaly because there is typically some sequential interdependence between modeling and drawing activities since drawings rely on models. Four other experts (Interviewees $\mathrm{F} / \mathrm{G} / \mathrm{I} / \mathrm{H} / \mathrm{N}$ ) agreed that in $\mathrm{DB}$ projects upon transfer of schematics design (SD) to the contractor, some sketches might be done in less complicated software such as sketch-up to explore some aspect of the design which will thereafter be implemented in the BIM model. For those aspects of design that are still being explored, implementing some SD decisions into DD model might lead to inefficiency because of changes.

Generally, quantity extraction efforts occur at every stage (Figures 8). Interviewee F stated 'it means quantity are being extracted at all phases...which is good'. Most of cost calculation efforts occurred at DD directed towards calculation, frequent review and final establishment of working budget using model-based estimation method.

Drawing activities occurred mostly at DD (architectural, structural and MEP drawings) and CD (working drawings) with the highest concentration at CD (Figures 8 and 9). Most of modeling activities occurred at DD and CD with peak at DD. The lack of modeling effort at pre-DD was clearly recognizable by the experts during the interviews. They agreed that this is because of DB procurement method used. The architects were engaged by the client to define the scope and design the project up to schematic design (SD) which formed the basis for tender and contractor selection. The effort curve is from the date of SD handover to the contractor. Thus, it is not unusual. Interviewee $\mathrm{N}$ added 'it tells us that we are still working traditionally with 
new concept called BIM because of procurement method and it is still common to find this distribution at early stage of adoption; it has some efficiency when compared with the non-BIM method'.

$<$ Insert Figure 10 somewhere here $>$

The experts agreed that the concentration of modeling effort at DD and early CD as well as the work pressure in both phases can be improved for greater process efficiency if subcontractors and suppliers are involved earlier in DD phase. One expert (Interviewee B) stated 'Subcontractors can be asked to give advice in DD' to reduce effort and pressure at $\mathrm{CD}$. Experts also agreed that the critical interface among tasks at DD can be optimized to reduce work pressure and inefficiency if SD models handed over by the architects are objects-based (Interviewee A/B/C). Currently, SD models by architects are often not of good quality therefore necessitating a lot of rework and work pressure at DD when the models are handed over. One expert (Interviewee C) states 'if BIM database is built early in SD phase before it is passed to us we should not be using too much effort in $D D^{\prime}$. Another expert described a situation where SD models handed to them by the Architect cannot be used at DD and had to be completely discarded. 'We have to start with full $2 \mathrm{D}$ drawings to resolve issues before we can start implementing the decision in DD model and it is a value slippage' the expert stated (Interviewee M). One expert (Interviewee J) stated that involving contractor early in the SD would bring greater efficiency by increasing the quality of SD models. Overall, project management effort is evenly distributed over the stages but with a peak at CD phase. This is not unusual because the input of several subcontractors and suppliers had to be coordinated at CD stage.

Generally, the initial stage of the BIM process absorbed a lower level of effort which involved initial project management activities. As the BIM process approached the start of DD, more efforts were absorbed by technical activities. As the BIM process progress to early $\mathrm{CD}$, the overall effort is lower than in the DD phase; but then the BIM process absorbed more working drawing effort (later part of CD) thereafter 
declining towards the end. However, project management was more intense at this stage up to post CD. The findings show that the amount of technical effort diminishes while management and coordination effort increased toward the end. Based on the discussions, the experts suggest that by moving more efforts from CD back to DD and from DD to SD would alleviate work pressure and bring greater efficiency.

$<$ Insert Figure 11 somewhere here $>$

\section{Practical uses of effort distribution analysis}

First, when the 13 experts were asked if aggregation of effort data on many projects is of any value, all the experts agreed that it can serve as a general guide, but any generalization provides little or no insight for continuous improvement of BIM workflow to achieve greater efficiency. Effort distribution depends on the context within which a BIM project is embedded, and the curve can only be meaningful when interpreted on a project-by project basis (Interviewees $\mathrm{D} / \mathrm{E} / \mathrm{I} / \mathrm{K}$ ). One expert said, 'Context information is necessary to explain any problem identified' (Interviewee $\mathrm{K}$ ). Projects are unique and tasks efforts distribution may vary widely for reasons beyond BIM use. Other external factors may impact the curve. For that reason, experts believed that the analysis should be used for all project and not just BIM projects.

Secondly, there was consensus that the analysis is currently not used in practice even though all the experts believed that it is an extremely useful assessment (Interviewees $\mathrm{D} / \mathrm{E} / \mathrm{F} / \mathrm{G} / \mathrm{H} / \mathrm{J} / \mathrm{K})$. Only one expert reported they collect person-hour data for all BIM activities. They have also developed a dashboard to visualize the breakdown of person-hours using charts and comparing actual to budget. The development has no functionality to explore effort distribution over project timeline (Interviewee $\mathrm{G}$ ). The company is a BIM engineering company providing BIM advisory services, modelling, BIM consultancy and research and development towards innovation. When asked why it is not currently used and the impact, one BIM specialist stated, 'In the past we were not doing this kind of control of process and we were losing money and I think it is because we were not doing internal assessment, we don't 
control time used on our activities and time is money' (Interviewee J). Two experts reported that their organization has just been bought by another company and performance assessment and monitoring has now been introduced across all their processes on projects (Interviewees $\mathrm{J} / \mathrm{K} /$ ).

Third, there was agreement that lack of awareness and organizational culture is one of the major barriers to using this kind of process post-mortem analysis on projects (all interviewees). One expert observed that effort distribution data can make employees perceive that teams are being measured and it may lead to lack of readiness by employees to report their effort accurately (Interviewee K). Employees are likely to view the data as sensoring that may lead to punishment and or which may affect their performance evaluation. Another expert stated, 'people already think BIM is extra workload and this analysis can be seen as added work and they won't think about the benefit even though it is extremely useful' (Interviewee F). One expert stated that the use of this approach would require an organizational culture where reporting and analysis of effort and the outcome is seen a positive process and endeavor (Interviewee K). Another barrier identified is that accounting system in many organisations is still business based and not project-based and so opportunity to identify inefficiency in projects processes are often missed (Interviewee J). Another expert stated that 'many people in our industry don't pursue business value.

Companies don't do things to look at value slippage and many practitioners are not entrepreneurial...they don't track money and hours. We should constantly be asking question, is it necessary, how can we do it faster and better, is there is difference between appreciated value and needed value? Is there a waste? We also need to know what is the number project by project...? (Interviewee $\mathrm{G})$.

Finally, when asked to describe the potential benefit of the analysis, one expert said, 'It is very useful and meaningful to know where and when your time is spent, and the analysis can give insight into where you need to invest your time' (Interviewee B). Other experts stated it is added value and can be used to understand costs and identify 
sources of variance between planned and actual effort and on that basis shed light into which processes to optimize (Interviewees $\mathrm{D} / \mathrm{E} / \mathrm{H} / \mathrm{K}$ ). Most of the experts also agreed that it can be part of project post-mortem analysis and lesson learned report which can help avoid work pressure, and unnecessary idleness on future projects. Another expert stated that 'It is really useful, but we don't do it, we just check the total cost we don't check each task to see if there is area to improve efficiency'(Interviewee H). This expert added it is useful because sometimes it is problematic when we think that a project is normal projects which is not and so this can help you plan fees.

Sometimes you can be too optimistic or forget things and so this analysis can help you look back and used the lessons to make better decision ... or even help you improve performance of process and assess the effect of what you did in the past' the expert added (Interviewee $\mathrm{H}$ ). Interviewee $\mathrm{G}$ currently use some result of man-hour analysis to help clients reduce their cost - 'with the knowledge of where time is spent, you can advise client on areas to invest their money [fees] depending on the context'. Some experts agreed that effort distribution charts can help them in lean planning and work planning which are often done at project start to manage interdependencies among tasks with the aim of optimizing resources (Interviewees $\mathrm{D} / \mathrm{E} / \mathrm{K}$ ). It is also thought that the outcome of effort analysis can be used to demonstrate efficiency to proof and justify to senior management the need to continue to invest in BIM (Interviewees $\mathrm{F} / \mathrm{G}$ ). It can also be used to motivate other employees who are reluctant towards BIM adoption (Interviewees F/G). One expert said, 'when we started BIM, this kind of statistics are not available and it the lack of proof make it hard to sell BIM to those who are not sure or management who are not BIM minded' (Interviewee F).

\section{DISCUSSION AND IMPLICATIONS OF THE FINDINGS}

\section{The influence of procurement}

The findings revealed a number of issues which also carry some implications for BIM innovation implementation and adoption by organizations and on projects, BIM 
policies, and procurement. While design-led procurement such as DB 'may provide an excellent opportunity to exploit BIM innovation, because a single entity is responsible for design and construction' as it is more cost-efficient and shorter than the DBB approach (Eastman et al.,2008), in this case study, the timing of contractorand subcontractor's involvement had an impact on interdependencies among tasks, effort distribution, risk of changes to the design models downstream and efficiency of the BIM process. First, the contractors were involved after the SD phase and were provided the SD model while the subcontractors were involved at early CD. As a result, effort was concentrated at DD and CD with most of the work pressure at DD stage. Effort peaked first at DD, it dropped and with a second peak at the end of CD creating two humps in the effort curve (see Figures 5 and 6). Considering the theoretical effort curve (Figure 3), the second peak is unexpected because in the ideal BIM workflow, DD phase should involve the design and all building systems fully and explicitly defined, coordinated and validated resulting in less effort at CD phase (AIA, 2007). It is expected that the designer spends more efforts on design and less in documentation and coordination when compared with non-BIM (2D CAD) workflow in which most efforts are spent on documentation.

Second, the theoretical effort curve assumes subcontractors input at DD phase (AIA, 2007). CD phase should ideally involve documentation of how the fully coordinated design will be built (AIA,2007). Several changes to- and development of- design model is not expected at CD because of the high cost of changes (Figure 3). In the case study, because of the lack of contractor's input at SD phase, many problems in the SD models had to be fixed during the DD phase including some sketching and 2D drawing effort prior to start of modelling task. Fixing model problems in the DD phase is not efficient(Banks,2015). Design models that are not set-up correctly at the onset can lead to unnecessary and costly efforts being expended to fix problem later. The experts interviewed observed that architects often do not set up SD models with construction in mind (Interviewees $\mathrm{G} / \mathrm{J} / \mathrm{N}$ ). Involving the contractor at SD phase and seeking sub-contractors advise at SD phase could have moved some effort upfront, 
promote greater efficiency by allowing early decision that can be implemented without needing change later at $\mathrm{DD}$ and $\mathrm{CD}$.

Moreover, several subcontractors were involved at $\mathrm{CD}$ phase thereby shifting more efforts to $\mathrm{CD}$ phase. In fact, the highest peak of project management effort occurred at $\mathrm{CD}$ arising from the need to coordinate several subcontractors' models and input (Figure 11). One of the experts stated 'We do lot at in the model at DD to define design decisions to get building permit [...] then once the sub-contractor comes in then changes start to surface because more subcontractors are getting involved. There may also be need for budget cut and there is inefficiency due to cost of changing models (Interviewee $G$ ). By involving subcontractors at DD could bring greater efficiency. Third, the need for changes at the $\mathrm{CD}$ phase can also arise from buildability issues identified by the site manager when the subcontractors' models are coordinated, contributing to the second hump in the effort curve. To eliminate this inefficiency, early involvement of the site manager at DD stage was deemed crucial for avoiding late changes at CD stage. Early involvement of suppliers in BIMenabled projects is an effort to minimize the interfaces between design and construction are key (Papadonikolaki et al. 2017, Papadonikolaki and Wamelink, 2017). Object-based designing and coordination of design at high level can start early bringing greater efficiency downstream.

Evidently, there is relationship between procurement, role and task interdependencies and BIM workflow efficiency. Although, Integrated Project Delivery (IPD), a very popular integrated procurement might be the most appropriate for BIM, it may not always be a feasible approach (Holzer, 2015). Nevertheless, other integrated approaches, such as supply chain partnering (Papadonikolaki et al. 2016, Papadonikolaki et al. 2017) could emulate early involvement through multi-party contracts and integration of the supply chain. The idealized effort distribution in a collaborative BIM workflow is built on the principles that early involvement of key project participants, early definition of project goals, intensified planning, open communication, use of appropriate technology to facilitate exchange of information 
seamlessly, and well-defined project organizational structure and leadership can lead to cheaper and better built assets constructed faster (AIA, 2007). While DBB would add to the fragmentation of information between design and construction, DB presents some potential opportunities for BIM use by increasing the potential for interfacing information between consultants and trade-contractors in construction documentation (Holzer, 2015). However, for greater efficiency in BIM-enabled DB workflow early involvement of contractors, subcontractors and suppliers is essential. At the project commencement, project team would need to agree on the timing and extent of involvement of each participant in a way that greater efficiency can be achieved.

\section{The effect of project coordination}

The case study used DB procurement which allowed greater opportunity to employ BIM efficiently by facilitating better coordination between design and construction model. Whilst the procurement governs 'design, construction and commissioning of projects' (Sebastian 2011) project coordination plays a crucial role in every project procurement and is needed for managing the tasks interdependences (Holzer, 2015) and for increasing the potential for interfacing information between design disciplines tasks and trade-contractors thereby minimize inefficiency. BIM use in DB requires skilled contractors who understand BIM workflows (Holzer 2015) and can coordinate the workflow efficiently. In the case study, the BIM coordination structure and the project management were highly centralized, stemming from the BIM managers. The BIM managers were responsible for modelling, drawings, working drawings, coordination, project management, quantity extraction and cost calculation (see Figure 4), which made the coordination structure simpler according to Olson et al. (1995), and more cost-efficient according to Malone (1987). The BIM managers also exerted control over the structural, MEP, sub-contractors' and suppliers' models. Besides their responsibility for many of tasks, the BIM managers performed an 'integrating manager' role (Olson et al. 1995). They exerted informal influence from their central position. The designer's and contractor's roles were less visible due to 
the role and power of the BIM manager. The project coordination structure appears to have helped manage the critical interface among tasks at DD phase (Figures 7 and 9) since all the tasks are occurring in-house within the same organization. However, this structure, whereas very controlled, would potentially have a greater vulnerability cost Malone (1987) as the BIM implementation control is solely dependent on one project actor.

During the interview with the 3 project actors who were involved (see Table 1), the challenges identified included time pressure because of late completion of tasks by external parties. The contractor's expectations were too high because it was their first BIM project, which also put work and time pressure on the other parties. The BIM managers had to work overtime to meet the requirements of their BIM management function. The centralized coordination structure facilitated the management of task interdependencies but also influenced the effort distribution curves. The implication is that in BIM workflow, parties would need to choose either a centralized coordination or a decentralized coordination. In a decentralized structure, more than one firm is responsible for coordination of BIM. Thus, the vulnerability cost is lower in decentralized structure than in centralized structure whereas coordination cost is higher in decentralized than centralized structures (Aibinu and Papadonikolaki, 2016). This would influence the effort curve. Nevertheless, the use of both 'centralized' and 'decentralized' BIM coordination structures could potentially contribute to greater development of BIM knowledge and higher BIM maturity across AEC firms.

\section{Effort distribution analysis, learning and BIM capability}

By discussing the result of effort distribution analysis including the curves with the three project actors as well 11 experts external to the project (14 interviews) it was possible to explore the characteristics of the curve by identifying anomalies. Context specific information enabled the identification of factors responsible for anomalies, unusual peaks, activities and critical interfaces among tasks and what could be done 
to achieve greater efficiency in the future. The effort curve in this study was also interpreted using the underlying concept of the MacLeamy curve (Figure 3). By aggregating effort distribution across many projects as proposed by MacLeamy (2004) curve, context information will be missed and the analyses will provide little information for real learning as aggregation only reflects outcomes while disregarding the inputs leading to that outcome whereas effort distribution study conducted on a project-by-project basis promotes better learning because it is a model of outcome and the associated inputs leading to the outcome. With effort distribution analytics, project managers or organizations can identify where efforts were utilized or track where efforts are being utilized and how.

According to the Project Management Body of Knowledge (PMBOK), implementing effort distribution analysis as part of project post-mortem or lesson learned process at the end of every project would allow continuous learning and improvement which can stimulate process innovation (PMI, 2013). The iterative learning process (Tatum, 1987) and combination of minor changes made over a prolonged time can bring about a significant workflow change and more efficient process which is quicker, faster and smarter (Williamson and Yin, 2014). This can increase an organization's BIM capability, improve project outcomes, bring savings and better returns on investment and ultimately organizational competitiveness. The improvement opportunities suggested by the 14 interviewees are more meaningful in practice and can be implemented on projects thereby making effort distribution a performance metric a very practical measure for assessing BIM implementation (Abdirad, 2017). For example, based on the effort curve (Figures 5,6, and 9) early contractor's and subcontractors' involvement at the SD phase, and early involvement of the site manager at DD are seeing by experts and project actors as a remedy for achieving greater efficiency. It can enable the project team build BIM database early using object-based modelling, achieve coordination among many design models earlier thus shifting effort upstream to SD phase and ultimately greater efficiency downstream at 
CD phase. This continuous cycle of learning can bring further innovation in the BIM process.

Relationship between effort distribution and project outcomes can also be explored and can be used to benchmark BIM performance across projects. Cluster analysis of the distribution using k-means clustering can be used to examine if there is relationship between the clustering and project and organizational outcomes. It can also be used to identify factors influencing the pattern: team size, project scale (complexity), frequency of changes in requirements, client's involvement level, type of projects.

\section{Contribution to knowledge, theory and methodology}

The contributions of this study are threefold. First, it offered new knowledge of BIM implementation and effort spent by setting the scene for greater understanding of effort distribution for various BIM related tasks which is lacking in the current literature. This dataset is unique and of further use and relevance to both scholars and practitioners. Second, from theoretical perspective, this is the first known study, to the best of the authors' knowledge, that conceptualized and operationalized effort distribution and its relation to task interdependencies, collaboration and efficiency in the context of BIM. Theoretically, this study revisited seminal theories from management and organization, e.g. Malone and Crowston (1994) on task interdependencies and Thompson (2003) on collaboration, and mobilised them in the context of BIM-based work to make a contribution to the field of construction management. Third, this theoretical contribution is accompanied by a contribution to methodology, as effort distribution was used as a tool to conceptualize and operationalize team collaboration, task interdependences and efficiency.

\section{Practical implications}

This study utilized effort distribution over a BIM-enabled project life cycle to conceptualize and operationalize how tasks are interrelated. The findings shed light 
not only on how to assess the performance of BIM process using effort distribution, but also how to visualize and understand the dynamics of team collaboration and interdependencies among tasks. It contributes to practice by proposing and testing a methodology that construction organizations can use to learn and innovate while implementing BIM. Apart from the contribution of the study to scholarship, the practical implications of the study relate to two main levels: project-level, and firmlevel, at both operational and day-to-day activities, as well as related to strategic decision-making in the following ways:

- Predictive and visual analytics using time-efforts data on projects can be a tool for project planning ex ante and post-hoc project evaluation as well as for managing team interaction efforts on project to achieve best outcomes. At any stage in the project life cycle, effort can be redistributed and reprioritized based on effort pattern detected, to rectify undesirable trends and avoid downstream problems.

- Effort distribution analytics can provide a guideline that BIM management team can use for developing an appropriate project schedule, deadlines and staffing level across project life cycle. Based on the staffing level requirement, organizational cash flow requirements can be determined and can serve as a useful basis for negotiating fee structures.

- Effort distribution analytics can support strategic decision-making around staff recruitment and training.

- Understanding time-effort distribution across various tasks and disciplines in a project would help project managers understand when each discipline should be engaged during the project life cycle and critical interfaces between disciplines.

- The research contribution also lies with the use of empirical data to explain how time-effort distribution can be used on BIM projects. 
- Effort distribution analysis can be used identify inefficiencies in the BIM process and to explore strategies for improving productivity by making BIM process more efficient. The inefficiency alert can help an organization when implementing corrective and preventive actions. It can support root-cause analysis process.

- Time distribution among activities can reflect BIM management decisions taken during BIM implementation as well as management styles and organizational attitude to BIM process.

- Visualizing effort distribution at any stage of a project could indicate future problems e.g. potential risks of changes in design or likelihood of design errors or clashes later in the project life cycle. It may also indicate potential for unnecessary rework in different areas e.g. remodeling.

- An analysis of effort distribution and the project outcomes can allow companies learn over time in regard to their BIM implementation process. It can be used to compare the performance of different BIM-based projects. It would also allow companies monitor the efficiency of their BIM implementation process. This is relevant because for new adopter there is not yet a single best practice BIM adoption strategy, and there may never be one. Thus, adopters of BIM need to find the most appropriate strategy that maximize the benefit for their organization and projects.

- Using effort distribution data collected over time on many projects can help identify optimal distribution of effort that leads to highest productivity as well as best project outcome.

- Effort distribution among BIM project activities over time can help provide insight into project dynamics from a resource allocation perspective. Project dynamics refers to the dynamics that occur on projects. The dynamics reflects how parties interact, communicate, and how the different aspects of the project interact and integrates to produce the project outcome over time. Project dynamics reflects the course a project takes. In a BIM project, BIM management plan would significantly impact on the dynamics of the project 
over time and would affect the resources consumed and efficiency of the project process and ultimately, the project outcome.

\section{CONCLUSION AND FUTURE WORK}

The research conducted sought to understand, conceptualize and operationalize BIM implementation and specifically how tasks efforts interrelate. After reviewing literature, it determined that effort distribution analytics is a relevant approach to address the research aim. Through a single in-depth case study, effort distribution analysis showed that drawing activities dominate BIM-based collaborative work (see Figure 4), and mainly during construction documentation (CD) phase (see Figure 5). The interrelationships between modeling effort and drawing effort are surprisingly accurate, there were some drawing activities prior to start of modelling. This can be explained by lack of contractors, subcontractors/suppliers input at the SD phase limiting the amount of object-based modeling at this stage because insufficient definition of the project details and in some instances design decisions at SD stage may not be buildable requiring some further sketching at DD stage whereas the ideal model-based process requires early definition of project goals, intensified planning, and open communication among key project participants. Instead of one, effort curve showed two humps, which is not as expected in a model-based process. To this end, the findings challenge the existing view that BIM is a panacea for quick production of documentation and efficient work. On the contrary, other factors influencing BIM implementation may contribute to low performance and change the behaviour of the effort distribution curve.

By seeking external validation of the study from a number of industry experts from the research context, the influence of procurement, project coordination structure and isolated tasks contribute to the complexity of the BIM process and might hinder its performance. Procurement influenced the timing of involvement of parties and the 
ability to effectively manage task interdependencies to achieve greater efficiency. To this end, early involvement of the site manager and suppliers/subcontractors, as well as organizational learning were deemed paramount for improving BIM implementation. This raises further question about the timing of involvement of various project participants and their role which can vary from project to project. These themes are highly topical, as BIM and digitalisation in construction are touted as solutions to the industry's inefficiencies, but they need a lot of fine-tuning before fully reaping their benefits. Apart from the theoretical relevance of the study, its practical implication is related to the deployment of effort distribution analytics to understand and potentially act upon the project execution, based on how tasks interdependencies unfold. The insight derived from effort distribution analytics can support iterative improvement in BIM implementation across projects to facilitate greater efficiency.

This study has several limitations. Project type, project size, team size across tasks and differences in BIM experience of teams might influence work-hours and effort distribution among tasks and how they are interrelated and used. This study did not examine these influences, but the methodology can be applied to all projects if data is available. Future study can examine these influences in more depth by applying the methodology of this study to more cases for calibration and further improvement of the proposed assessment approach of effort in BIM-based work. The data used for this study is limited; for instance, the data does not separate time effort expended on on making changes to the models at DD and CD stages. This could provide greater insight into the influence of procurement on effort distribution and areas of inefficiency. A comparison between planned effort and actual effort would also be useful, which this study did not examine due to lack of data. Future research will use more projects to replicate the methodology developed and in different settings e.g. different procurement routes and in different countries, to calibrate the model and seek ways to inform our understanding and assessment of how BIM implementation unfolds. 


\section{REFERENCES}

Abdirad, H., 2017. Metric-based BIM implementation assessment: a review of research and practice. Architectural Engineering and Design Management, 13:1, 52-78, DOI: 10.1080/17452007.2016.1183474

AIA's G202 - 2013., Project BIM Protocol Form. Exhibit M http://architectis.it/onewebmedia/AIA \%C2\%AE\%20Document $\% 20 \mathrm{G} 202 \mathrm{TM}$ \%20\%E2\%80\%93\%202013.pdf [accessed 20/5/2018]

AIA National and AIA California Council, 2007. The American Institute of Architects. Integrated Project Delivery: A Guide. 2007 Version 1.

Aibinu, A.A. and Papadonikolaki, E., 2016. BIM Implementation and Project Coordination in Design-Build Procurement. In P. Chan \& C.J. Neilson (eds.) Proceedings of the 32nd Annual ARCOM Conference. Manchester, UK: Association of Researchers in Construction Management 15-24.

Aibinu, A. \& Venkatesh, S., 2014. Status of BIM adoption and the BIM experience of cost consultants in Australia. Journal of Professional Issues in Engineering Education and Practice, 140, 04013021.

Aibinu, A.A., de Jong, P., Wamelink, H. and Koutamanis, A., 2014. Using Effort Distribution Analysis to Evaluate the Performance of Building Information Modeling Process. In Raymond Issa R. and Ian Flood (eds.), Proceedings of the 2014 International Conference on Computing in Civil and Building Engineering. ICCCBE ${ }^{2014}$. Walt Disney World in Orlando, Florida, USA. June 23-25, 2014, pp. $73-80$.

Aranda-Mena, G., Crawford, J., Chevez, A. and Froese, T., 2009. Building information modeling demystified: does it make business sense to adopt BIM? International Journal of Managing Projects in Business. 2(3), 2009, 419-433.

Azhar, S., 2011. Building Information Modeling (BIM): Trends, benefits, risks and challenges for the AEC industry. Leadership and Management in Engineering, 11, 241-252.

Azzouz, A., Hill, P. \& Papadonikolaki, E., 2018. Digital innovation in europe: regional differences across one international firm. Association of Researchers in Construction Management Conference. Belfast, UK: Annual conference of the Association of Researchers in Construction Management.

Banks, J., 2015. Why BIM is Still Bankrupting Your Firm. Shoegnome Architects, Available at http://www.shoegnome.com/2015/12/09/bim-still-bankruptingfirm/ [accessed 25th February 2018].

Barlish, K., and Sullivan, K., 2012. How to measure the benefits of BIM - A case study approach. Automation in Construction, 24, 149-159. doi:http://dx.doi.org/10.1016/j.autcon.2012.02.008

Berlo, L. V., Beetz, J., Bos, P., Hendriks, H., \& Tongeren, R. v. 2012 Collaborative engineering with IFC: new insights and technology. Paper presented at the 9th European Conference on Product and Process Modelling (ECPPM 2012), Reykjavik, Iceland. 
Berlo, L.V. \& Papadonikolaki, E., 2016. Facilitating the BIM coordinator and empowering the suppliers with automated data compliance checking. In S.E. Christodoulou \& R. Scherer (eds.) Proceedings of the 11th European Conference on Product and Process Modelling (ECPPM 2016). Limassol, Cyprus: CRC Press 145-153.

BIM dictionary. https://bimdictionary.com/. (n.d.). In: BIM Dictionary. [online] BIMe Initiative. Available at: https://bimdictionary.com/ [Accessed 13 Apr. 2018].

Blaikie, N. 2010. Designing Social Research. Polity Press.

Bryde, D., Broquetas, M., Volm, J.M., 2013. The project benefits of Building Information Modeling (BIM). International Journal of Project Management, Volume 31, Issue 7, Pages 971-980.

BuildingSmart, 2015. Common InfraBIM requirements YIV2015. Available at: https://buildingsmart.fi/wpcontent/uploads/2016/11/YIV2015 VOL $02 \quad 201509$ 14-ENGLISH.pdf [accessed $9^{\text {th }}$ of June 2018].

Campbell, J. P., Dunnette, M., \& Hough, L. M., 1990. Handbook of industrial and Organizational Psychology. CA: Consulting Psychologists.

Cerovsek, T., 2011. A review and outlook for a 'Building Information Model'(BIM): A multi-standpoint framework for technological development. Advanced engineering informatics, 25(2), 224-244. doi:http://dx.doi.org/10.1016/j.aei.2010.06.003

Cheng, Y.M., Yu, C.H., and Wang, H.T., 2011. Short-Interval Dynamic Forecasting for Actual S-curve in the Construction Phase. Journal of Construction Engineering and Management, 137(11), 933-941.

Computer Integrated Construction (CIC) Research Program, 2012. "BIM Planning Guide for Facility Owners," Pennsylvania State University: University Park, PA

Creswell, J. W., 1994. Research design: Qualitative \& quantitative approaches. Thousand Oaks, California, USA: Sage Publications.

Dossick, C.S. \& Neff, G., 2010. Organizational divisions in BIM-enabled commercial construction. Journal of construction engineering and management, 136, 459467.

Dowsett, R.M. \& Harty, C.F., 2018. Assessing the implementation of BIM - an information systems approach AU. Construction Management and Economics, 1-16, DOI: 10.1080/01446193.2018.1476728

Eastman, C., Teicholz, P., Sacks, R., \& Liston, K., 2008. BIM Handbook: A Guide to Building Information Modeling for Owners, Managers, Designers, Engineers, and Contractors (Second ed.). Hoboken, New Jersey, USA: John Wiley \& Sons Inc.

Eastman, C., Teicholz, P., Sacks, R., \& Liston, K., 2011. BIM handbook: A guide to building information modeling for owners, managers, designers, engineers and contractors (2nd ed.). Hoboken, NJ: Wiley.

Engwall, M., 2012. PERT, Polaris, and the realities of project execution. International Journal of Managing Projects in Business, 5(4), 595-616. 
Fleishman, E.A, Gebhardt, D.L., and Hogan, J.C., 1984. The measurement of effort. Ergonomics, 27 (9), 947 -954.

Giel, B. and Issa, R., 2013. Return on Investment Analysis of Using Building Information Modeling in Construction. Journal of Computing in Civil Engineering, 27(5), 511-521.

Grytting, I., Svalestuen, F., Lohne, J., Sommerseth, H., Augdal, S., and Lædre, O., 2017. Use of LoD decision plan in BIM-projects, Procedia Engineering, Volume 196, pp. 407-414.

Harris, T.J., Seppala, C.T. and Desborough, L.D., 1999. A review of performance monitoring and assessment techniques for univariate and multivariate control systems. Journal of Process Control, Volume 9, Issue 1, Pages 1-17.

Harrison, D. H., 2010. "Building Digital Bridges: Improving Digital Collaboration through the Principles of Hyperlinked Practice". PhD thesis, Victoria University of Wellington, viewed 28th March 2018, $<$ http://researcharchive.vuw.ac.nz/xmlui/handle/10063/2020?show=full $>$.

Higgin, G., \& Jessop, N., 1965. Communications in the building industry: The report of a pilot study. London: Routledge.

HMGovernment., 2015. Digital Built Britain, Level 3 BIM Strategic Plan. Retrieved from http://digital-builtbritain.com/DigitalBuiltBritainLevel3BuildingInformationModellingStrategic $\underline{\text { Plan.pdf }}$

Holzer, D., 2015, December 2-4. BIM for procurement - Procuring for BIM. Paper presented at the 49th International Conference of the Architectural Science Association: Living and Learning: Research for a Better Built Environment (ANZAScA 2015), Melbourne, Australia.

Indiana University Architect's Office (2009) Building Information Modeling (BIM) Guidelines and Standards for Architects, Engineers, and Contractor.

Jaradat, S., Whyte, J., \& Luck, R., 2013. Professionalism in digitally mediated project work. Building Research and Information, 41(1), 51-59. doi:http://dx.doi.org/10.1080/09613218.2013.743398

Jones, C., 2004. Software Project Management Practices: Failure Versus Success. Available: http://www.pauldee.org/se-must-have/jones-failure-success.pdf (accessed 25th March 2018).

Kagioglou, M., Cooper, R., and Aouad, G., 2001. Performance management in construction: a conceptual framework. Construction Management and Economics, 19(1): 85-95. doi:10.1080/01446190010003425.

Kaka, A. P., 1999. The development of a benchmark model that uses historical data for monitoring he progress of current construction projects. Engineering. Construction and Architectural Management, 6(3), 256-266.

Kam, C., Song, M.H, Senaratna, D., 2013. VDC Scorecard: Formulation, Application, and Validation. Journal of Construction Engineering and Management, 143,3, 04016100-1- 9.

Kassem, M. \& Succar, B., 2017. Macro BIM adoption: Comparative market analysis. Automation in Construction, 81, 286-299. 
Kokkonen, A. \& Alin, P., 2016. Practitioners deconstructing and reconstructing practices when responding to the implementation of BIM AU. Construction Management and Economics, 34, 578-591, DOI: 10.1080/01446193.2016.1164327

Kshirsagar, A.M. and Smith, W.B., 1995. Growth Curves. Marcel Dekker, Inc., pp. 157.

Kueng, P. and Krahn, A.J.W., 1999. Building a Process Performance Measurement System: some early experiences, Journal of Scientific \& Industrial Research, Vol. 58, No. 3/4, pp. 149-159.

Kumar, K., and vanDissel, H. G., 1996. Sustainable collaboration: Managing conflict and cooperation in interorganizational systems. MIS Quarterly, 20(3), 279300.

Lainhart IV, J. W., 2000. Why IT governance is a top management issue. The Journal of Corporate Accounting \& Finance, Volume 11, 5, pp 33-40.

Lambrecht, J. F., 2017. Measuring the effects of using the IT concept: A research project conducted in cooperation with GenieBelt. Retrieved from Copenhagen, Denmark:

Liu, Y., van Nederveen, S., \& Hertogh, M., 2016. Understanding effects of BIM on collaborative design and construction: An empirical study in China. International Journal of Project Management. Vol. 35, No.4, pp. 686-698.

Lu, W., Fung, A., Peng, Y., Liang, C and Rowlinson, S., 2014. Cost-benefit analysis of Building Information Modeling implementation in building projects through demystification of time-effort distribution curves. Building and Environment, Volume 82, 2014, Pages 317-327.

Lu, W., Fung, A., Peng, Y., Liang, C and Rowlinson, S., 2015. Demystifying Construction Project Time-Effort Distribution Curves: BIM and Non-BIM Comparison. Journal of Management in Engineering, Volume 31,6, Pages 04015010-1 - 04015010-8.

McLeamy, P., 2004. Collaboration, Integrated Information, and the Project Lifecycle in Building Design and Construction and Operation. In: Introduced in the Construction Users Roundtable's WP-1202.

Malone, T. W., 1987. Modeling Coordination in Organizations and Markets. Management Sciemce, 33(10), 1317-1332.

Malone, T. W., \& Crowston, K., 1994. The Interdisciplinary Study of Coordination. ACM Computing Surveys, 26(1), 87-119. doi:Doi 10.1145/174666.174668.

Manning R, Messner J (2008). Case studies in BIM implementation for programming of healthcare facilities, ITcon Vol. 13, Special issue Case studies of BIM use, pg. 246-257, http://www.itcon.org/2008/18

Maxwell, J.A. \& Mittapalli, K., 2010. Realism as a stance for mixed methods research. Handbook of mixed methods in social \& behavioral research, 145168.

Mcgraw-hill Construction, 2008. Building Information Modeling (BIM): Transforming Design and Construction to Achieve Greater Industry Productivity, in Building Information Modeling Trends SmartMarket Report. McGraw-Hill: NY. 
McGraw-Hill., 2014. The business value of BIM for Construction in Major Global Markets: How Contractors Around the World are driving Innovation with Bilding Information Modeling (D. a. C. Intelligence, Trans.). In H. M. Bernstein (Ed.), Smart Market Report: McGraw Hill Construction.

McGraw Hill Construction, 2012. The Business Value of BIM in North America: Multi-Year Trend Analysis and User Ratings (2007-2012). Smart Market Report. Retrieved from http://bradleybim.files.wordpress.com/2012/12/2012 bim smartmarket repor $\mathrm{t}$ business value of bim in north america.pdf (accessed 7 Feb 2014).

Miettinen, R., \& Paavola, S., 2014. Beyond the BIM utopia: Approaches to the development and implementation of building information modeling. Automation in Construction, 43, 84-91. doi:http://dx.doi.org/10.1016/j.autcon.2014.03.009.

Milanović Glavan, Lj., 2011. Understanding Process Performance Measurement systems. Business Systems Research, Vol 2 No. 2, pp. 1-56.

Miles, M.B. \& Huberman, A.M., 1994. Qualitative data analysis: An expanded sourcebook Thousant Oaks, CA: Sage Publications Inc.

Mom, M. and Hsieh, S.H., 2012. Towards Performance Assessment of BIM Technology Implementation, Proceeding of the 14th International Conference on Computing in Civil and Building Engineering, June 27-29, Moscow, Russia.

Morgan, B., 2017. Organizing for Digitization in firms: A multiple level perspective. In: P.W. Chan \& C.J. Neilson, eds. Proceedings of the 33RD Annual Association of Researchers in Construction Management Conference (ARCOM 2017), Cambridge, UK: Association of Researchers in Construction Management.

Nørkjaer Gade, A., Otrel-Cass, K. \& Svidt, K., 2018. A holistic analysis of a BIMmediated building design process using activity theory AU. Construction Management and Economics, 1-15, DOI: 10.1080/01446193.2018.1533644

Olson, E. M., Walker Jr, O. C., and Ruekert, R. W., 1995. Organizing for effective new product development: The moderating role of product innovativeness. The Journal of Marketing, 59(1), 48-62.

Oraee, M., Hosseini, M. R., Papadonikolaki, E., Palliyaguru, R., \& Arashpour, M., 2017. Collaboration in BIM-based construction networks: A bibliometricqualitative literature review. International Journal of Project Management, 35(7), 1288-1301. doi:https://doi.org/10.1016/j.ijproman.2017.07.001

Papadonikolaki, E. \& Wamelink, H., 2017. Inter- and intra-organizational conditions for supply chain integration with BIM. Building Research \& Information, 1 16.

Papadonikolaki, E., Vrijhoef, R. \& Wamelink, H., 2015. BIM adoption in integrated Supply Chains: A multiple case study. In: A.B. Raidén \& E. Aboagye-Nimo, eds. Proceedings of the 31st Annual Association of Researchers in Construction Management Conference (ARCOM 2015), Lincoln, UK: Association of Researchers in Construction Management, 631-640. 
Papadonikolaki, E., Vrijhoef, R. \& Wamelink, H., 2016. The interdependences of BIM and supply chain partnering: Empirical explorations. Architectural Engineering and Design Management.

Papadonikolaki, E., Verbraeck, A. \& Wamelink, H., 2017. Formal and informal relations within BIM-enabled supply chain partnerships. Construction Management and Economics, 1-22.

Paulson, B. C., 1976. Designing to reduce construction costs. Journal of the Construction Division, 102(C04)

PMI, 2013. A guide to the Project Management Body of Knowledge (PMBOK Guide) Newtown Square, Pennsylvania: Project Management Institute Standards Committee.

Poirier, E. A.Staub-French, S. and Forgues, D., 2015. Assessing the performance of the building information modeling (BIM) implementation process within a small specialty contracting enterprise. Canadian Journal of Civil Engineering. 42 (10), pp. 766-778.

Pourshahid, A., 2008. Toward an Integrated User Requirements Notation Framework and Tool for Business Process Management, the 2008 International MCETECH Conference one-Technologies, pp. 3-15.

Sarantakos, S., 2005. Social Research, $3^{\text {rd }}$ edn, Palgrave Macmillan, Basingstoke, p.86.

Sebastian, R., 2011. "BIM in different methods of project delivery." Proceedings of the CIB W078-W102 Joint Conference: Computer, Knowledge, Building, A. Zarli, B. Fiès, C. Egbu, M. M. A. Khalfan, and R. Amor, eds.Sophia Antipolis, France, 800-809.

Sebastian, R. \& Berlo, L.van, 2010. Tool for Benchmarking BIM Performance of Design, Engineering and Construction Firms in The Netherlands. Architectural Engineering and Design Management. 6 :254-263.

Skitmore, M., 1998. A method for forecasting owner monthly construction project expenditure flow. Journal of Forecasting, 14, 17-34.

Software Engineering Institute (SEI). Capability maturity model integrated (CMMI) for Development, Version 1.2.

Succar, B., 2010. Building Information Modeling maturity matrix. Chapter in Handbook of Research on Building Information Modeling and Construction Informatics: Concepts and Technologies, 2nd Ed., Information Science Publishing, Hershey, PA., 65-103.

Succar, B., Sher, W., and Williams, A., 2013. An integrated approach to BIM competency assessment, acquisition and application. Automation in Construction, 35: 174-189. doi:10.1016/j.autcon.2013.05.016.

Succar B., 2009. Building information modelling framework: a research and delivery foundation for industry stakeholders. Automation in Construction, Vol.18, No.3, 357-375.

Tagen S., 2004. Performance measurement: from philosophy to practice. International Journal of Productivity and Performance Management, Vol. 53, No. 8, pp. $726-737$ 
Tatum, C. B., 1987. Innovation on the construction project: a process view. Project Management Journal, 18(5), 57-67.

Thompson, J. D., 2003. Organizations in action : social science bases of administrative theory, Transaction Publishers, New Brunswick, NJ.

Viney, D., 2005. The Internet Portal Guide: How to Make the Business Case for a Corporate Portal, Then Successfully Deliver, Mercury Web Publishing, London.

Williamson, P.J. and Yin, E., 2014. Accelerated innovation: The new challenge from China. MIT Sloan Management Review, 55(4), p.27.

Yeo, G.B., and Neal, A., 2004. A Multilevel Analysis of Effort, Practice, and Performance: Effects of Ability, Conscientiousness, and Goal Orientation. Journal of Applied Psychology, 89, 2, pp. 231-247.

Table 1 - Interviewees' participating in the data interpretation step (step 4) profiles 


\begin{tabular}{|c|c|c|c|c|}
\hline $\begin{array}{l}\text { Identifier } \\
\text { of } \\
\text { interviewee }\end{array}$ & $\begin{array}{l}\text { Interviewee } \\
\text { Background }\end{array}$ & $\begin{array}{l}\text { Years of } \\
\text { Experience }\end{array}$ & Type of firm & Role in the project \\
\hline $\mathrm{A}$ & $\begin{array}{l}\text { Cost } \\
\text { Manager }\end{array}$ & 17 years & $\begin{array}{l}\text { BIM Consultancy/Cost } \\
\text { Management }\end{array}$ & Cost Manager/Quantity Take-off \\
\hline B & $\begin{array}{l}\text { Director and } \\
\text { Owner }\end{array}$ & 30 years & $\begin{array}{l}\text { BIM } \\
\text { Consultancy/Contractor } \\
\text { /Cost Management }\end{array}$ & $\begin{array}{l}\text { Project Management/ Cost } \\
\text { Manager/ }\end{array}$ \\
\hline $\mathrm{C}$ & $\begin{array}{l}\text { BIM } \\
\text { Consultant } \\
\text { and } \\
\text { Innovation } \\
\text { Manager }\end{array}$ & 7 years & $\begin{array}{l}\text { BIM } \\
\text { Consultancy/Contractor } \\
\text { /Cost Management }\end{array}$ & $\begin{array}{l}\text { Project management/BIM } \\
\text { Management }\end{array}$ \\
\hline $\mathrm{D}$ & $\begin{array}{l}\text { BIM } \\
\text { Manager }\end{array}$ & 22 years & $\begin{array}{l}\text { Architectural Design and } \\
\text { Consultancy }\end{array}$ & Independent interviewee \\
\hline $\mathrm{E}$ & $\begin{array}{l}\text { BIM } \\
\text { Coordinator } \\
\text { and } \\
\text { Architectural } \\
\text { Engineer }\end{array}$ & 7 years & $\begin{array}{l}\text { Architectural Design and } \\
\text { Consultancy }\end{array}$ & Independent interviewee \\
\hline $\mathrm{F}$ & $\begin{array}{l}\text { BIM } \\
\text { Specialists }\end{array}$ & 18 years & BIM Consultancy & Independent interviewee \\
\hline G & $\begin{array}{l}\text { Owner and } \\
\text { BIM } \\
\text { Manager }\end{array}$ & 10 years & BIM Consultancy & Independent interviewee \\
\hline $\mathrm{H}$ & $\begin{array}{l}\text { Structural } \\
\text { Engineer and } \\
\text { VDC } \\
\text { Specialist }\end{array}$ & 9 years & $\begin{array}{l}\text { International Engineering } \\
\text { and Project Management } \\
\text { Consultancy }\end{array}$ & Independent interviewee \\
\hline $\mathrm{I}$ & $\begin{array}{l}\text { Architectural } \\
\text { Engineer }\end{array}$ & 10 years & Asset Management & Independent interviewee \\
\hline $\mathrm{J}$ & $\begin{array}{l}\text { BIM } \\
\text { Specialist }\end{array}$ & 15 years & Contractor & Independent interviewee \\
\hline K & $\begin{array}{l}\text { BIM } \\
\text { Specialist }\end{array}$ & 11 years & Contractor & Independent interviewee \\
\hline $\mathrm{L}$ & $\begin{array}{l}\text { Project } \\
\text { Manager }\end{array}$ & 14 years & Contractor & Independent interviewee \\
\hline $\mathrm{M}$ & $\begin{array}{l}\text { BIM- } \\
\text { Modeler }\end{array}$ & 5 years & Contractor & Independent interviewee \\
\hline
\end{tabular}




\begin{tabular}{|l|l|l|l|l|}
\hline $\mathrm{N}$ & BIM & 5 years & BIM Consultancy /Real & Independent interviewee \\
& Consultant & & \\
for & Estate Advisory \& & \\
Construction & & & \\
and Real & & & \\
Estate & & & \\
\hline
\end{tabular}




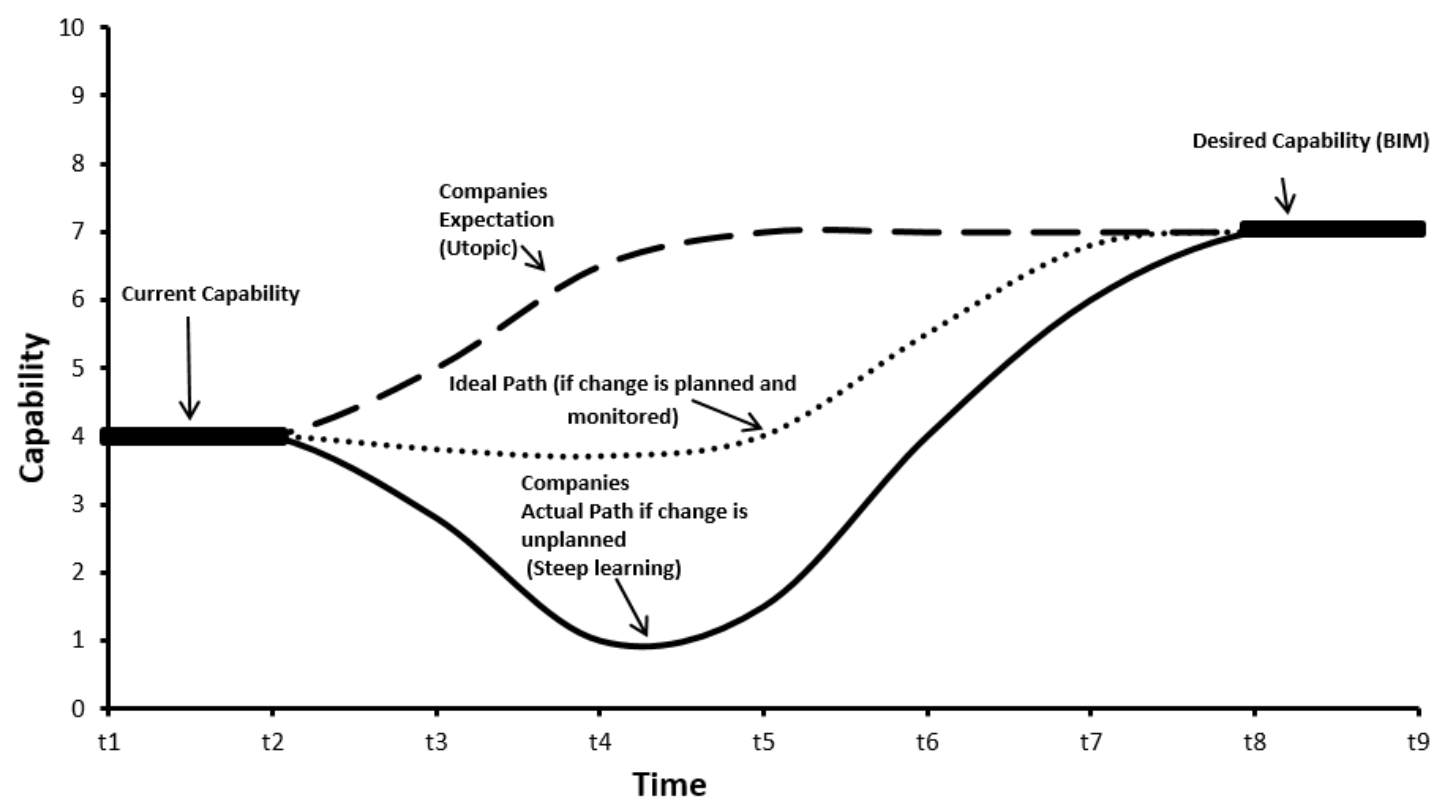

Figure 1: The J-curve of BIM implementation process (Adapted from Viney, 2005)

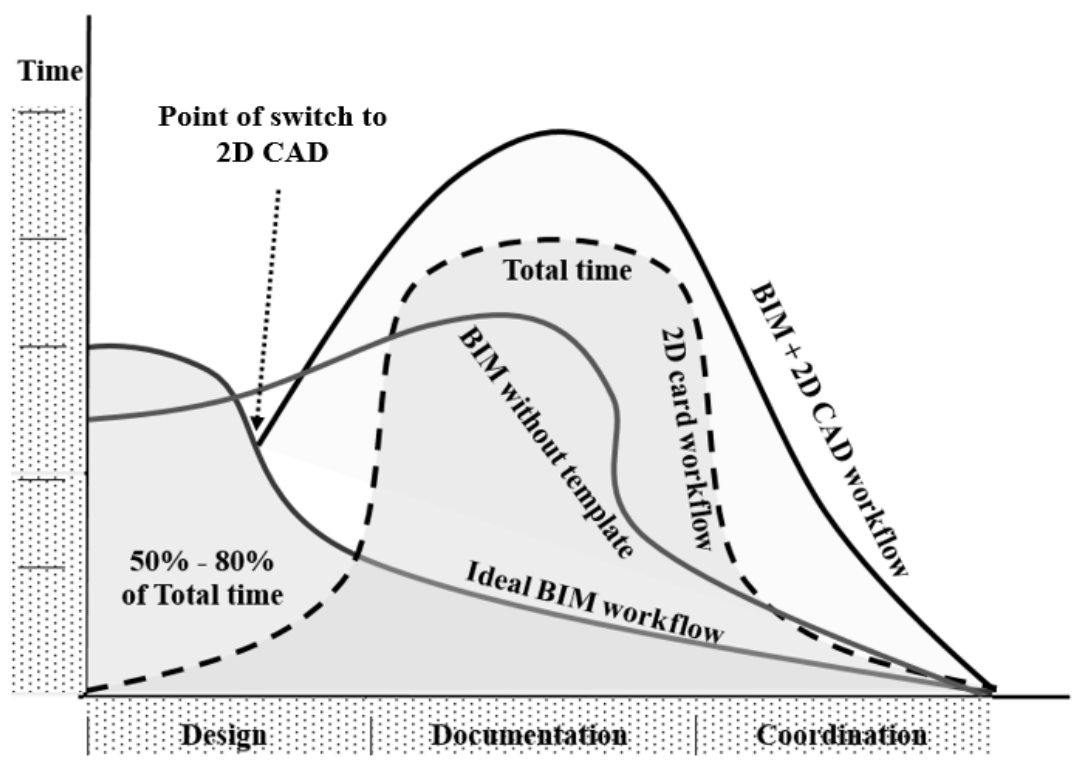

Figure 2: Comparison of efforts in different design stage workflow (Source: authors; adapted from Banks 2015) 


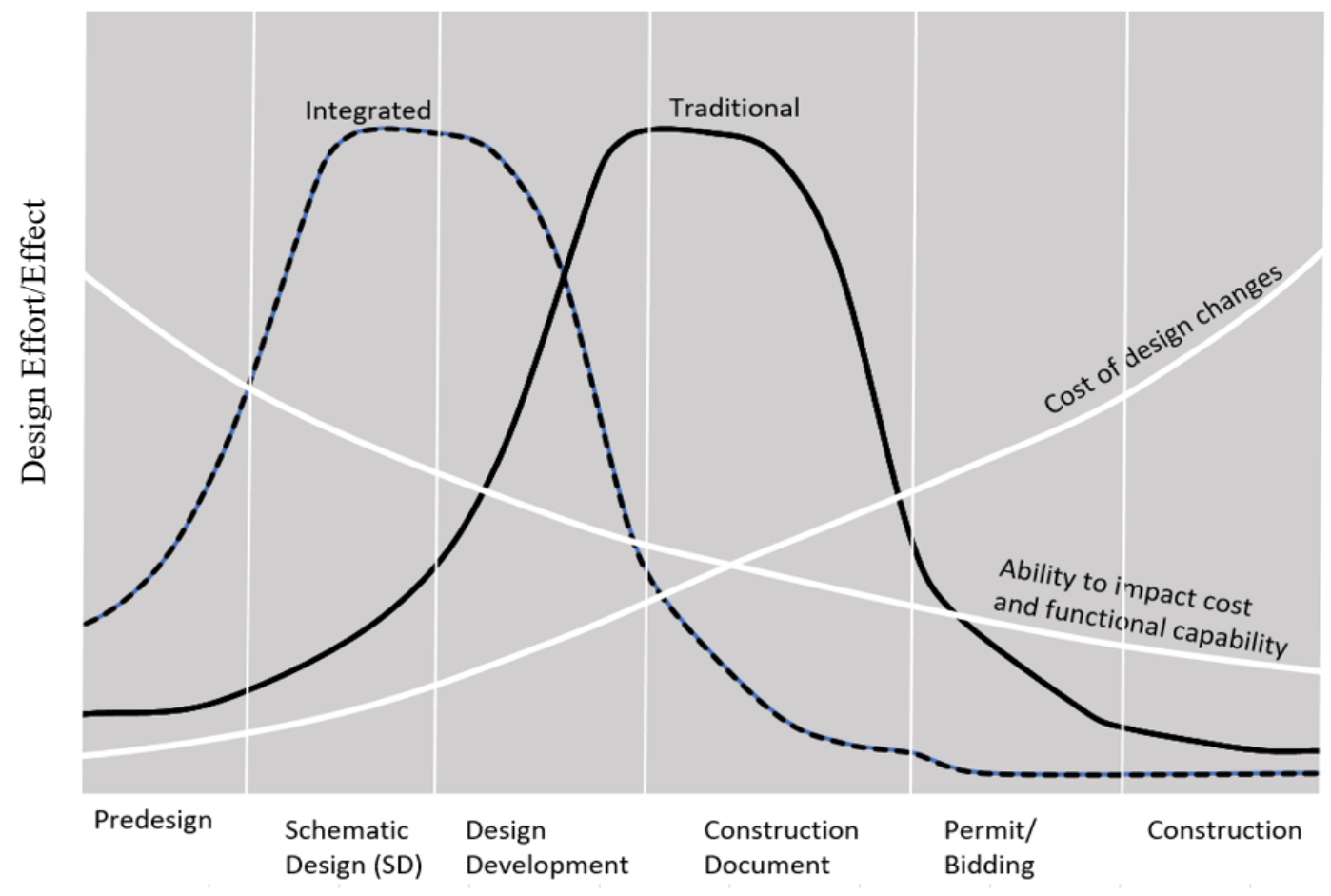

Figure 3: The MacLeamy Curve (Source: authors; adapted from AIA, 2007) 


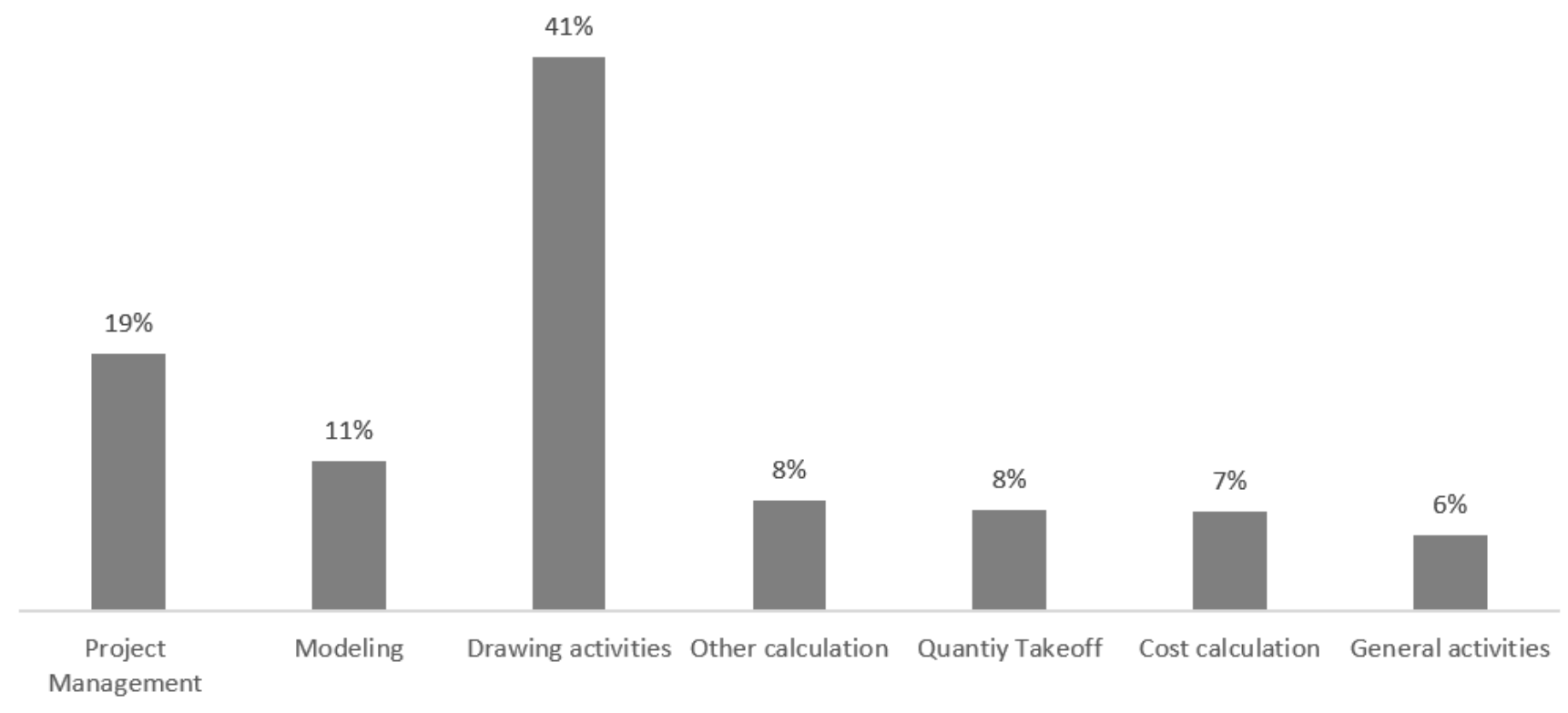

Figure 4: Breakdown of Effort per Tasks as a \% of total effort

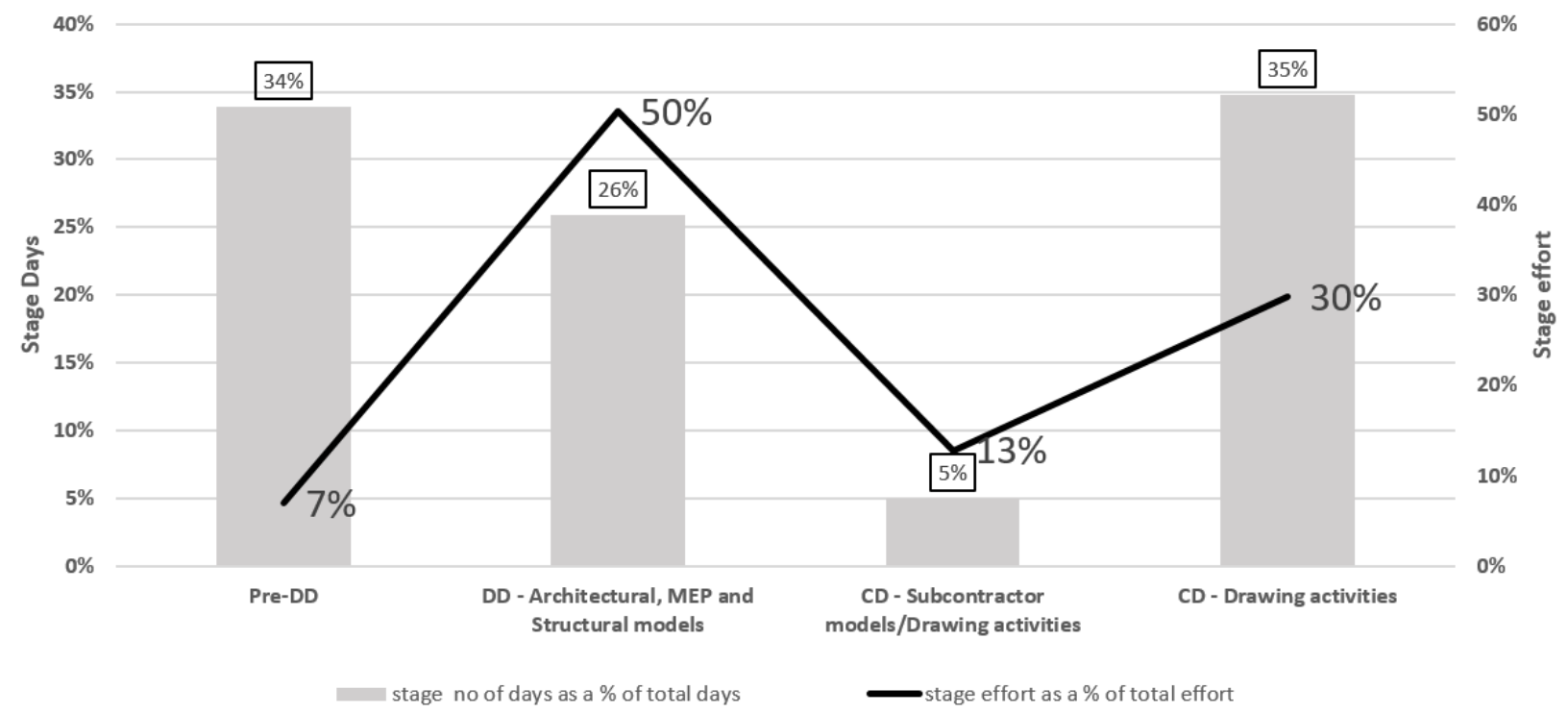

Figure 5: Breakdown of stages by $\%$ of total number of days and by $\%$ of total effort 


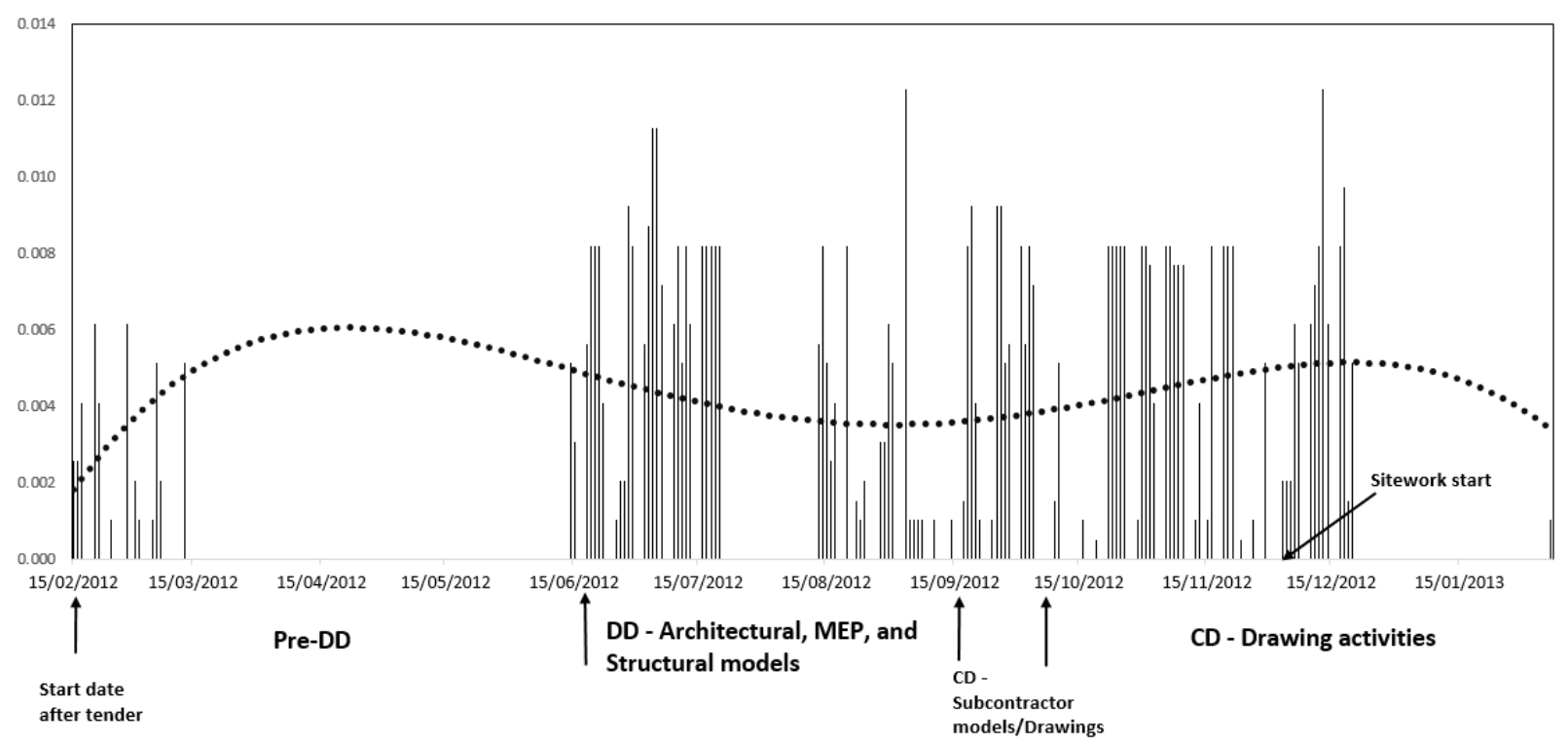

Figure 6: Total effort distribution visualization for Project A tasks fitted with a polynomial trend line.

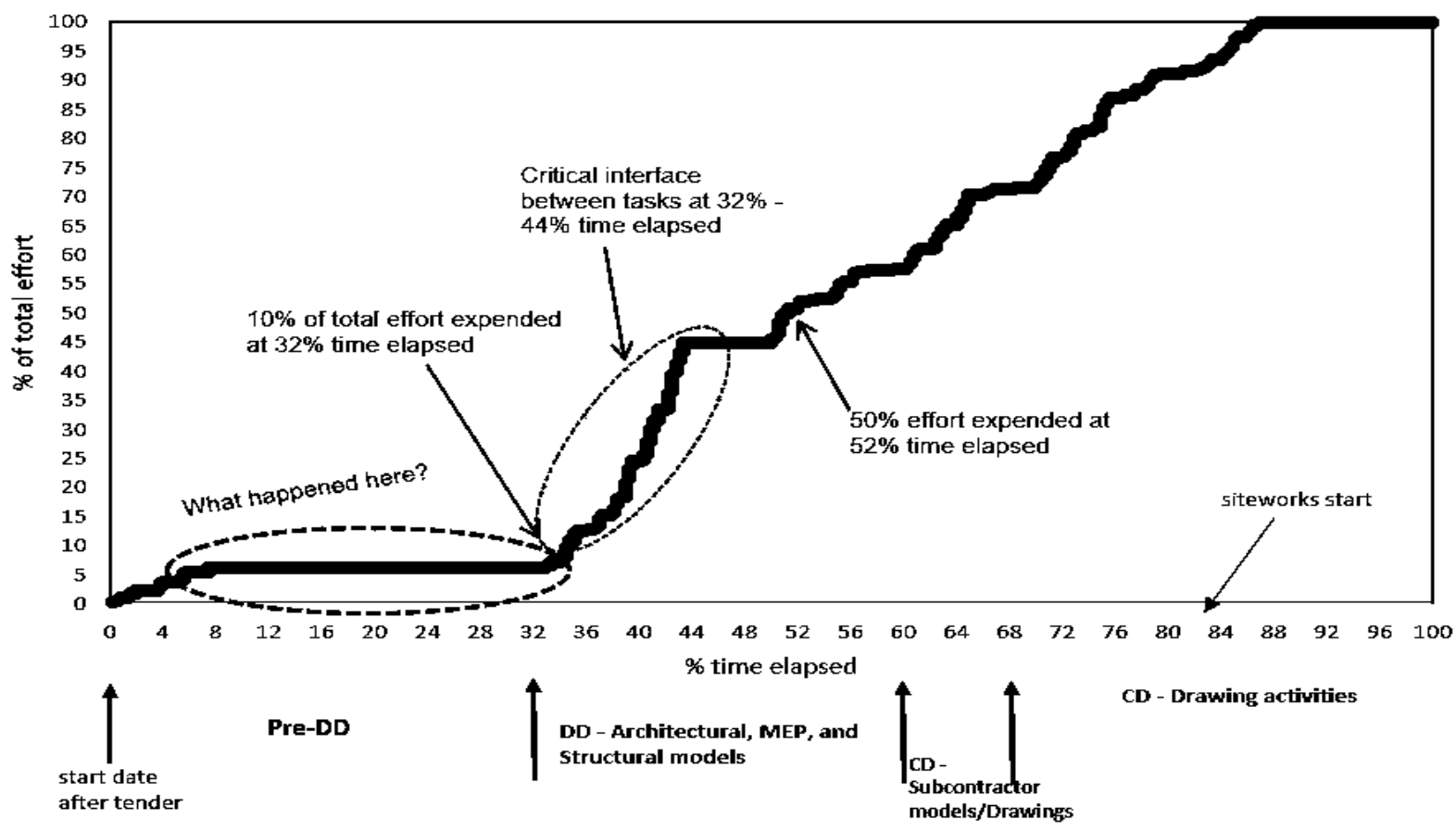

Figure 7: Cumulative percentage total effort versus percentage time elapsed 


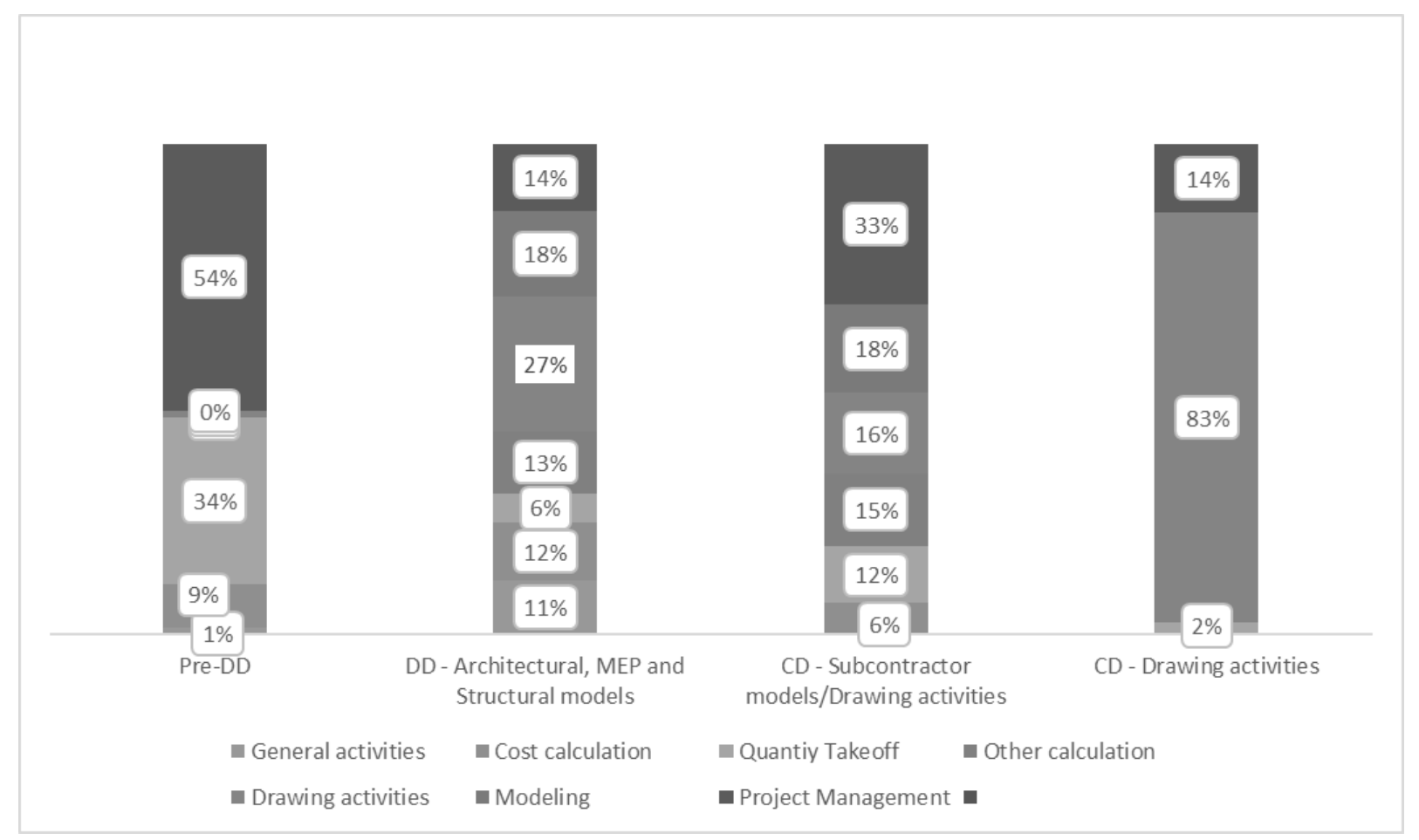

Figure 8: Effort expended on tasks as \% of total stage effort

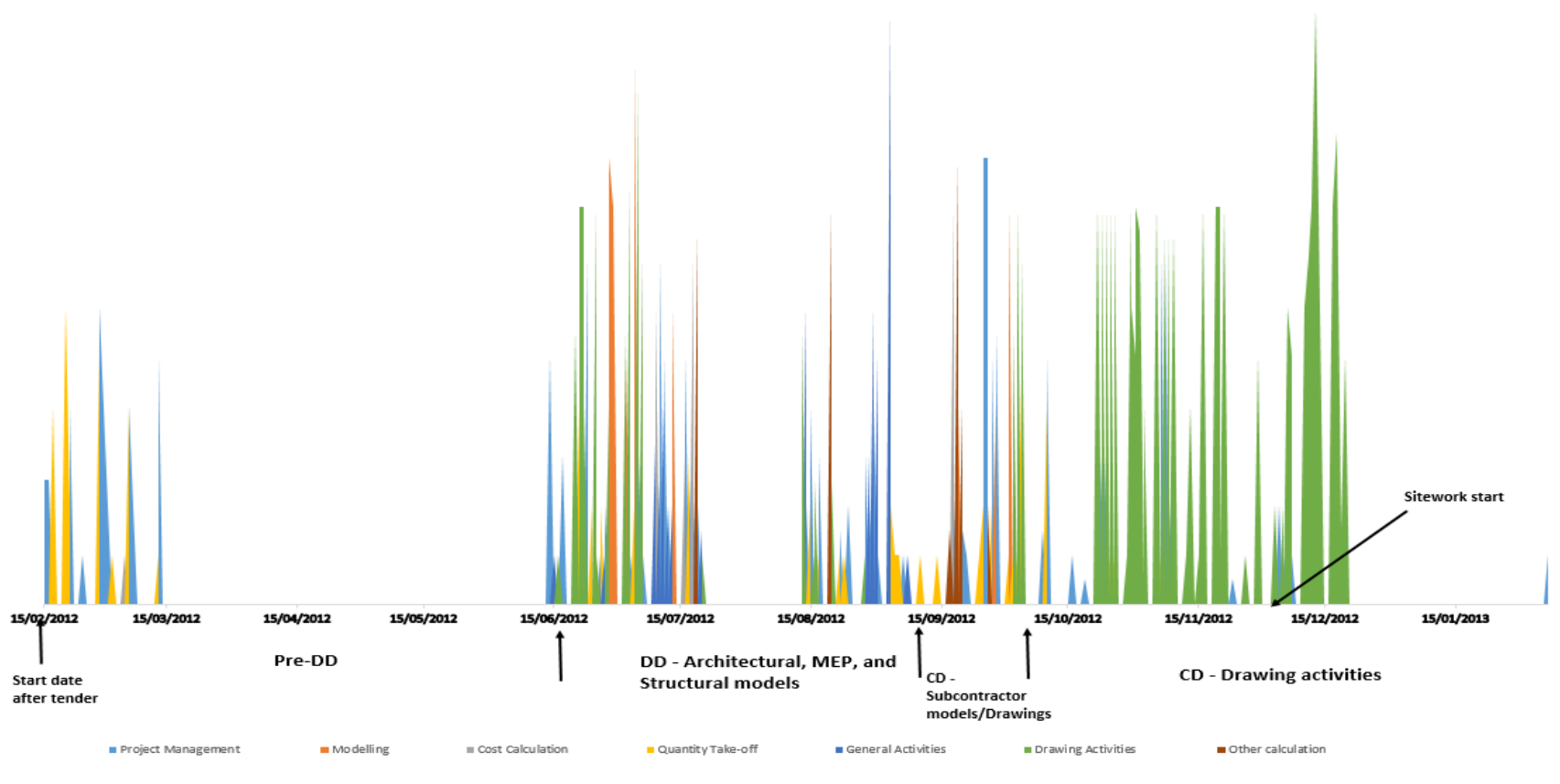

Figure 9: Effort distribution visualization for Project A showing interdependencies among tasks 


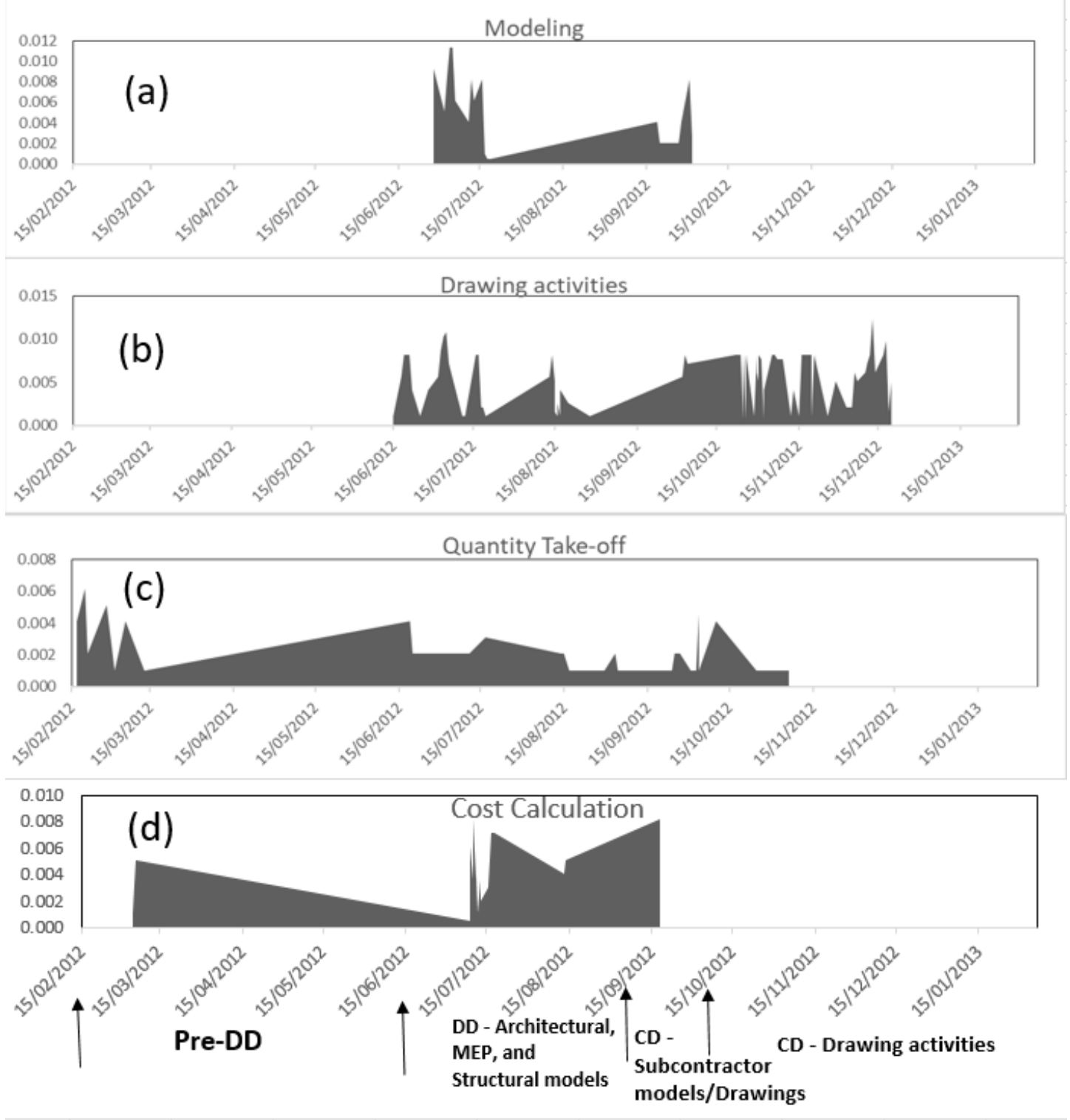

Figure 10: Effort distribution chart for modelling, drawing activities, quantity takeoff, cost calculation 

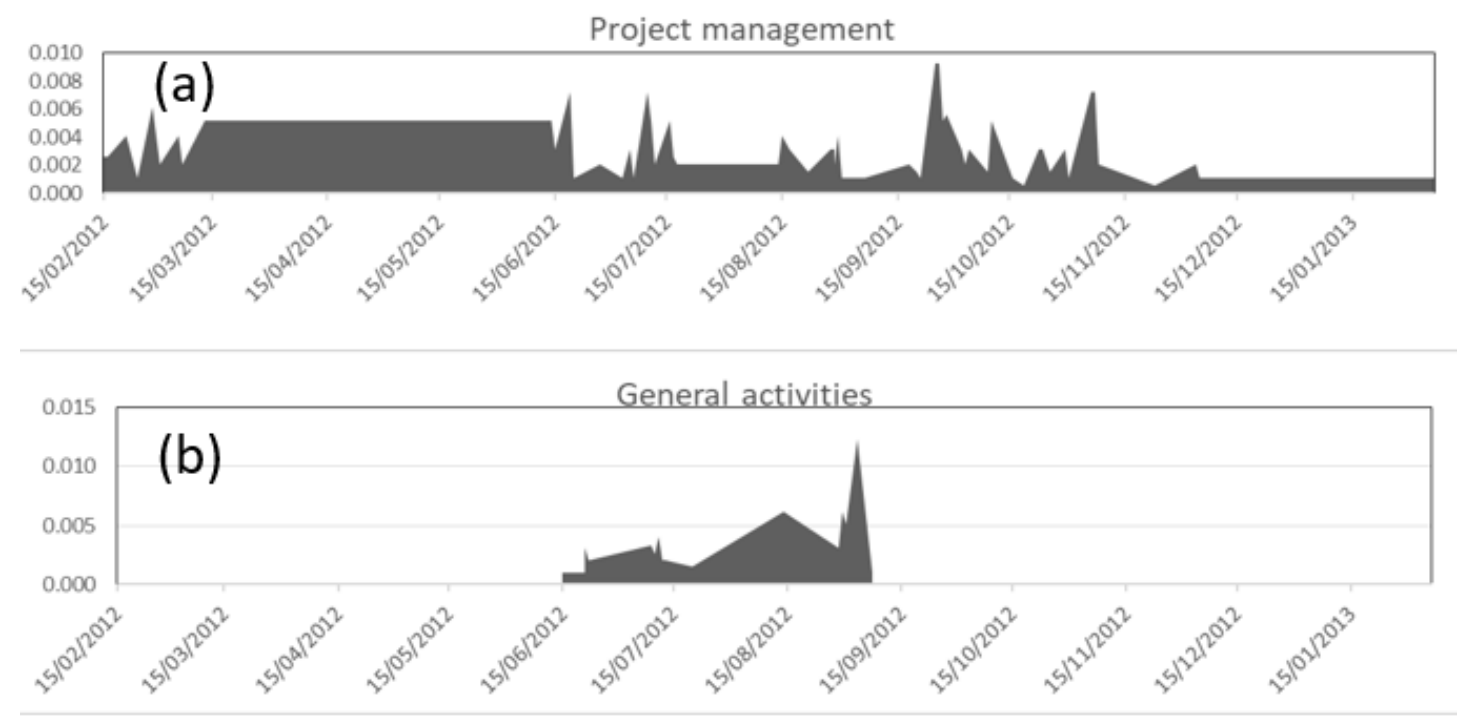

Other calculations

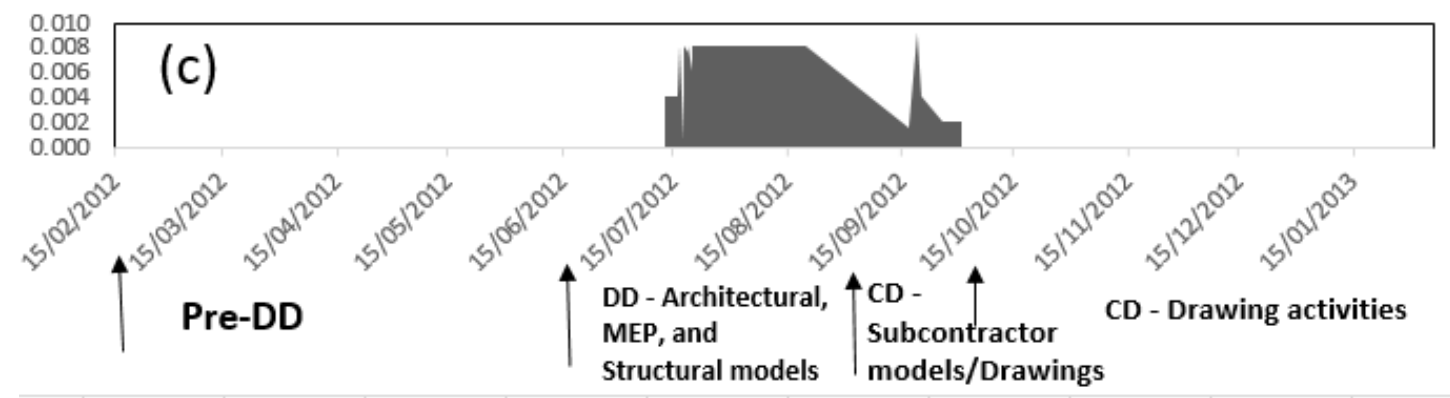

Figure 11: Effort distribution chart for project management, general activities, other calculations 


\section{$\underline{\text { Figure captions }}$}

Figure 1: The J-curve of BIM implementation process

Figure 2: Comparison of efforts in different design stage workflow (Source: authors; adapted from Banks 2015)

Figure 3: The MacLeamy Curve (Source: authors; adapted from AIA, 2007)

Figure 4: Breakdown of Effort per Tasks as a \% of total effort

Figure 5: Breakdown of stages by $\%$ of total number of days and by $\%$ of total effort

Figure 6: Total effort distribution visualization for Project A tasks fitted with a polynomial trend line.

Figure 7: Cumulative percentage total effort versus percentage time elapsed

Figure 8: Effort expended on tasks as \% of total stage effort

Figure 9: Effort distribution visualization for Project A showing interdependencies among tasks

Figure 10: Effort distribution chart for modelling, drawing activities, quantity takeoff, cost calculation

Figure 11: Effort distribution chart for project management, general activities, other calculations 


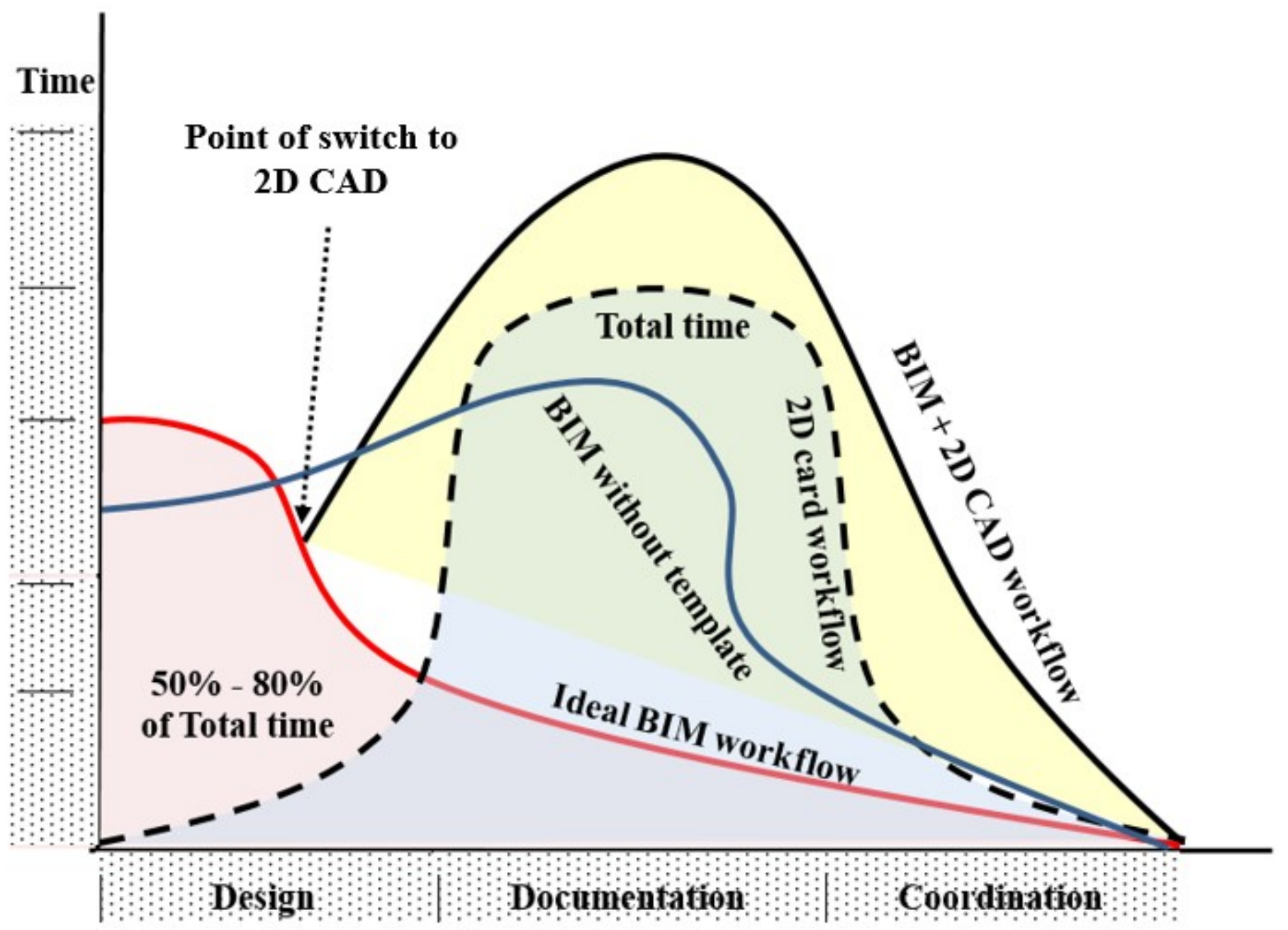


$19 \%$

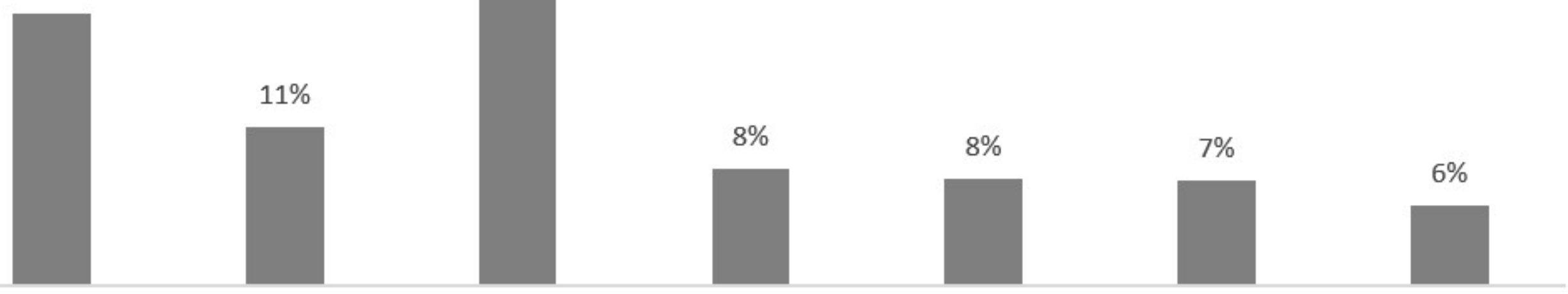

Project Modeling

Drawing activities Other calculation

Quantiy Takeoff

Cost calculation

General activities Management 


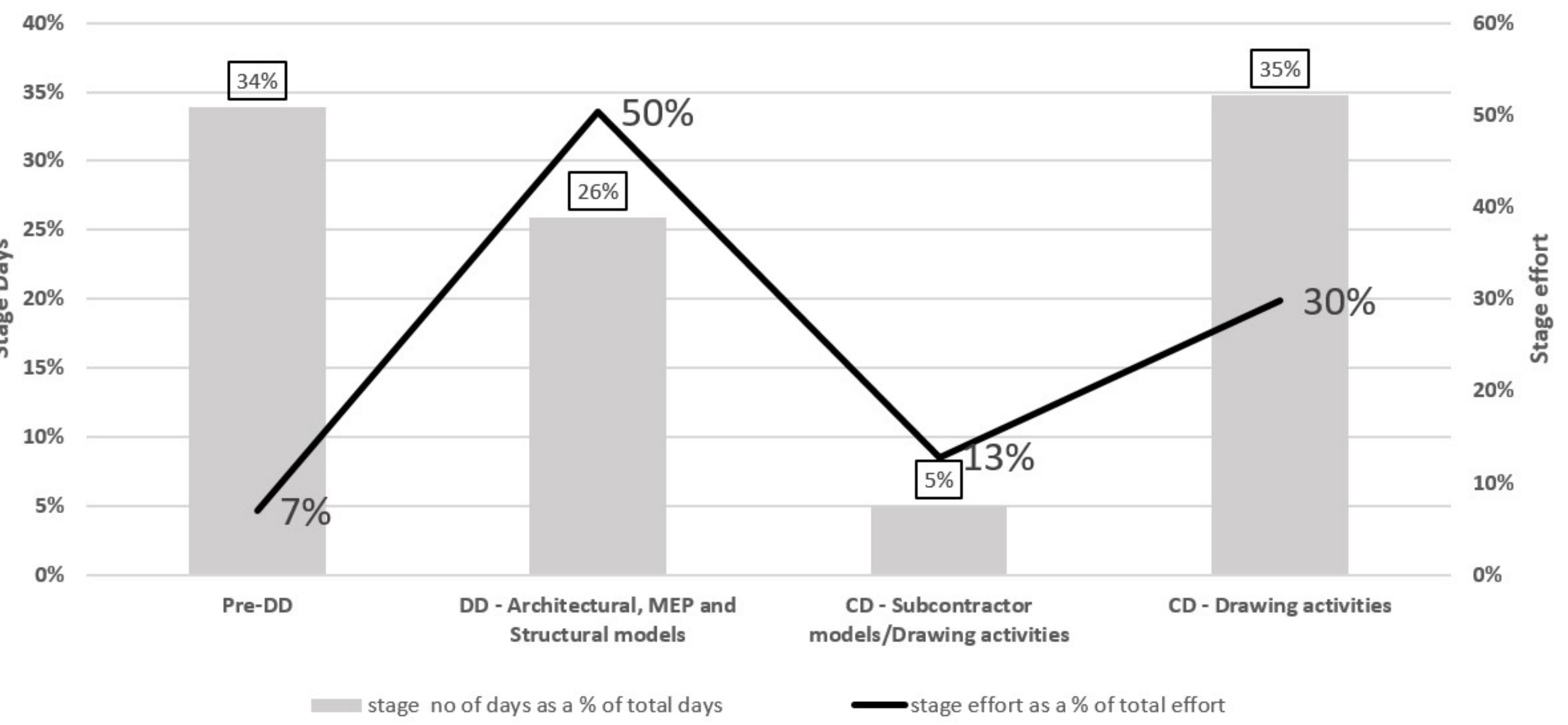




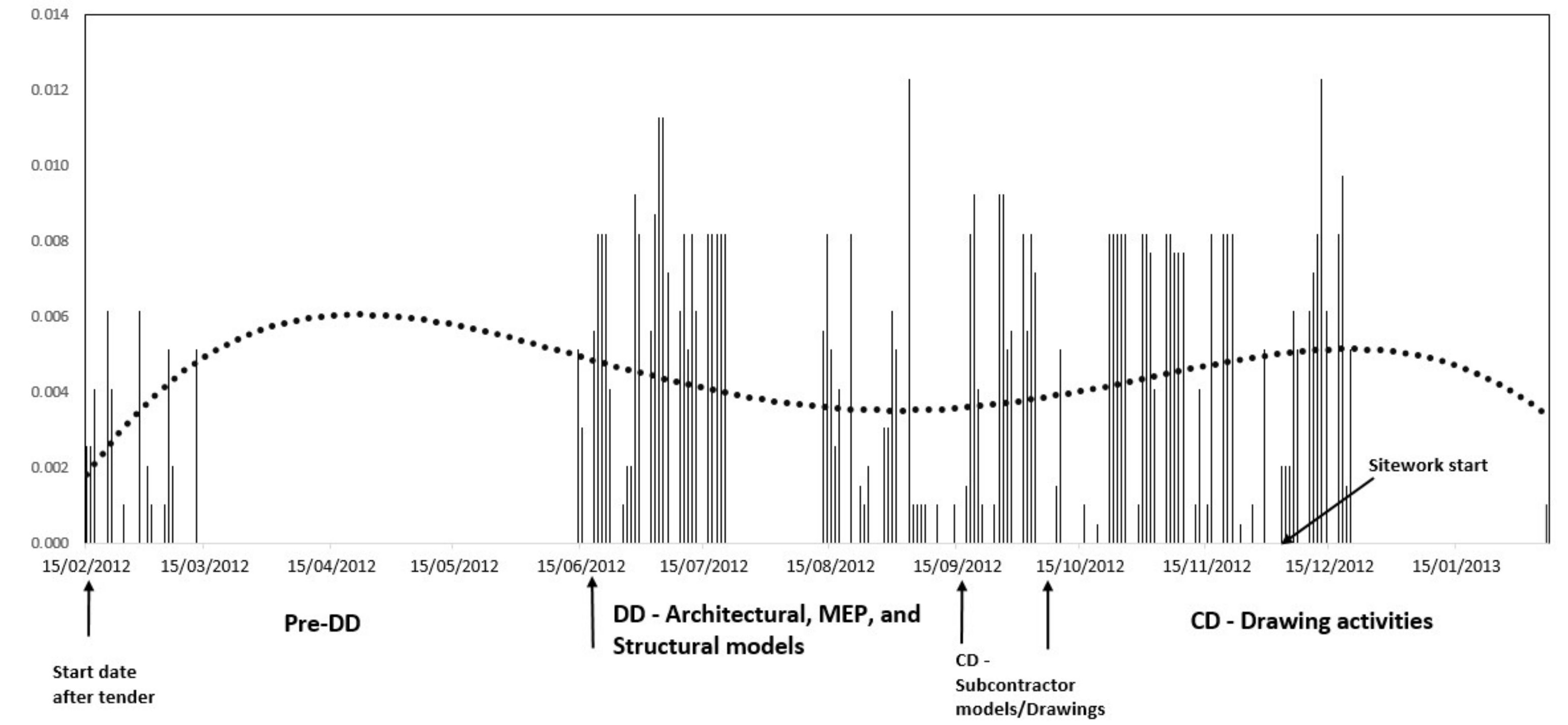




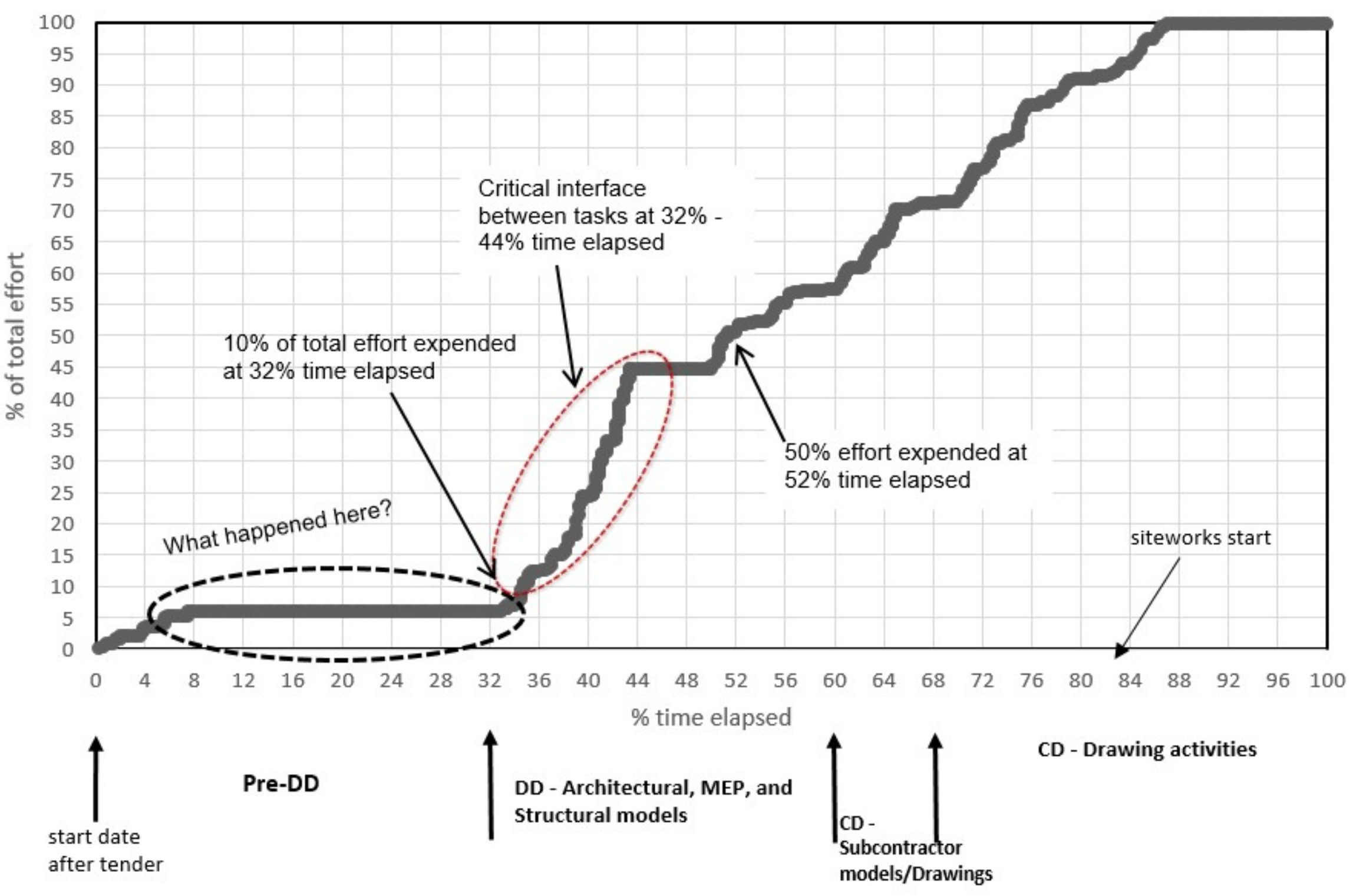




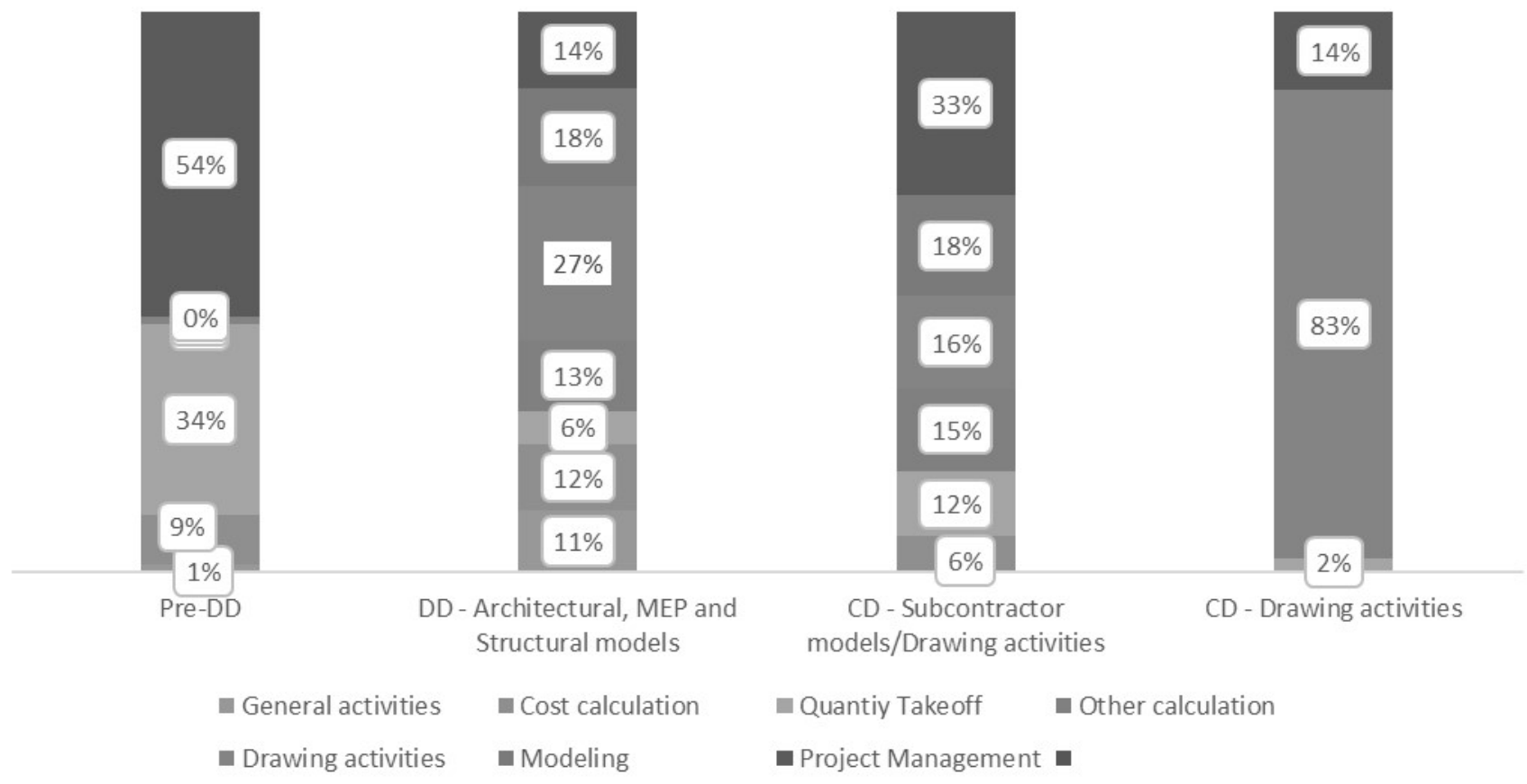




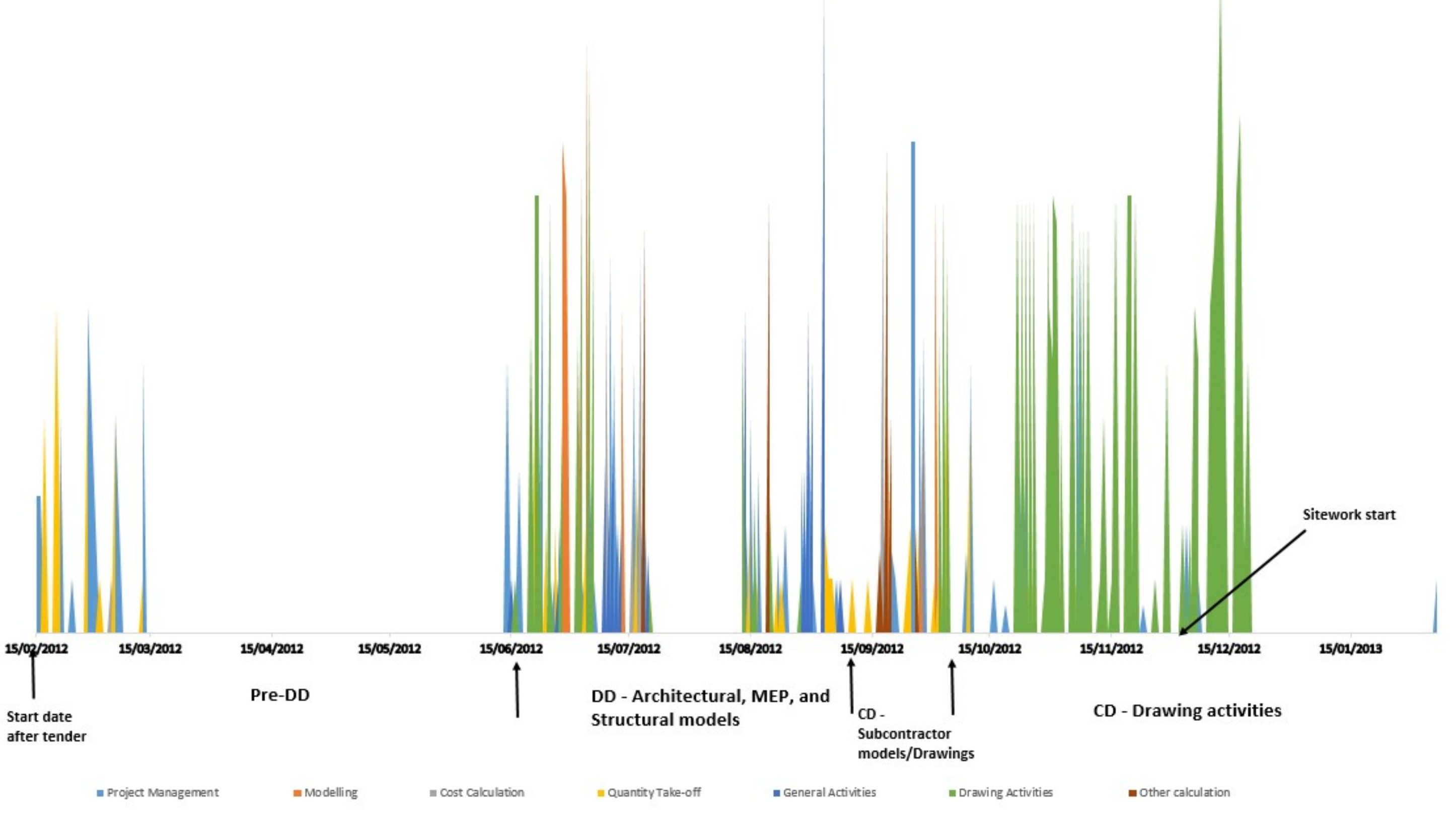




\section{Modeling}

(a)
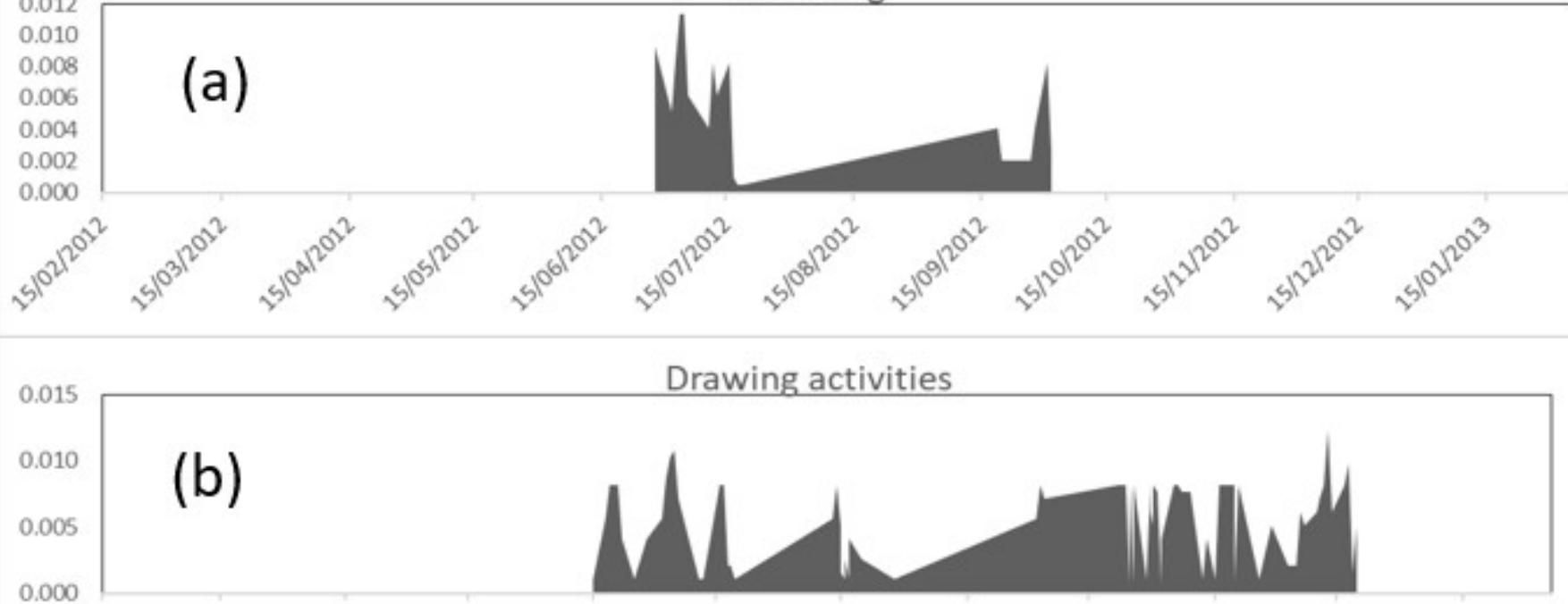

0.000
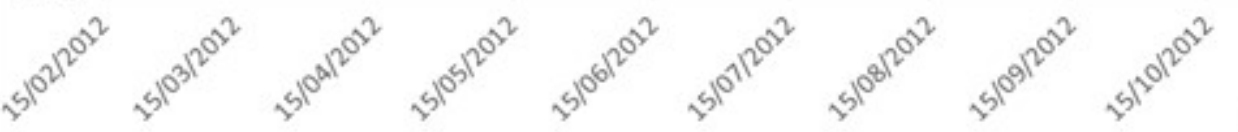

Quantity Take-off
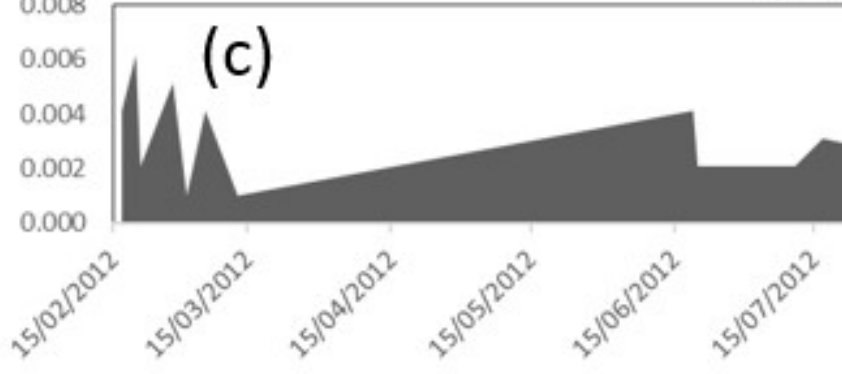

0.010 0.008 0.006 0.004 0.002 0.000

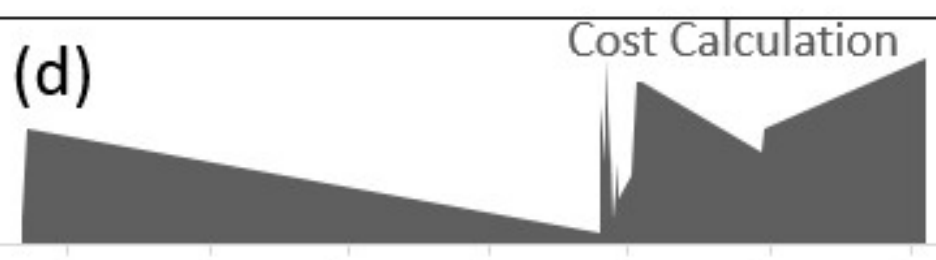
$50^{2}$

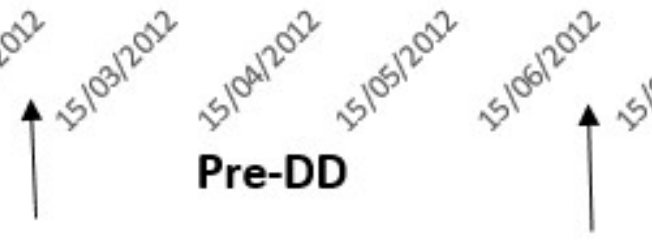

CD - 
